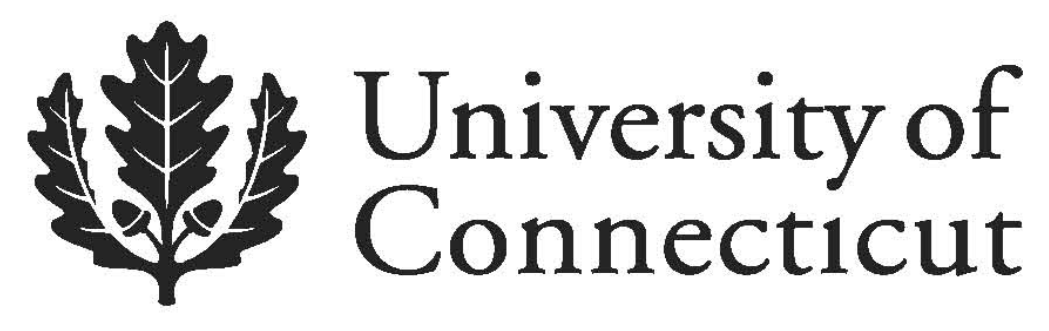

Department of Economics Working Paper Series

\title{
Purchasing Power Parity between the UK and the Euro Area
}

Girogio Canarella

California State University, Los Angeles

Stephen M. Miller

University of Nevada-Las Vegas

University of Connecticut

Stephen K. Pollard

California State University, Los Angeles

Working Paper 2012-45

November 2012

365 Fairfield Way, Unit 1063

Storrs, CT 06269-1063

Phone: (860) 486-3022

Fax: (860) 486-4463

http://www.econ.uconn.edu/

This working paper is indexed on RePEc, http://repec.org 


\title{
Purchasing Power Parity between the UK and the Euro Area
}

\author{
Giorgio Canarella \\ California State University, Los Angeles \\ Los Angeles, CA 90032 \\ gcanare@calstatela.edu \\ University of Nevada, Las Vegas \\ Las Vegas, Nevada, USA 89154-6005 \\ giorgio.canarella@unlv.edu \\ Stephen M. Miller* \\ University of Nevada, Las Vegas \\ Las Vegas, Nevada, USA 89154-6005 \\ stephen.miller@unlv.edu \\ Stephen K. Pollard \\ California State University, Los Angeles \\ Los Angeles, CA 90032 \\ spollar2@calstatela.edu
}

\begin{abstract}
We use the Johansen cointegration approach to assess the empirical validity of the purchasing power parity (PPP) between the UK and the Euro Area, which we represent by Germany, the largest of its members. We conduct the empirical analysis in the context of the global financial crisis that began in 2007 and find that it directly affects the cointegration space. We fail to validate the Johansen and Juselius (1992) original hypothesis that nonstationarity of the PPP associates with the nonstationarity of interest rate differentials to produce a stationary relation. On the other hand, we do not reject PPP. We find that PPP cointegrates with inflation differentials. We also find, contrary to conventional wisdom, that (i) equilibrium adjustment occurs between the German and UK inflation rates, while weak exogeneity exists for the German and UK interest rates and the PPP condition, and (ii) three common trends associated with the German interest rate, the UK interest rate, and the PPP condition "push" the system with the German interest rate and the PPP condition playing dominant roles.
\end{abstract}

Keywords: Purchasing Power Parity, Euro Area, Cointegrated VAR.

JEL Classifications: E31, E43, F31, F32

* $\quad$ Corresponding author. 


\section{Introduction}

Purchasing power parity (PPP) proves a most controversial hypothesis in the international finance literature. A key component of a number of theoretical models, such as flexible-price monetary models (Frankel, 1976; Mussa, 1976), sticky-price monetary models (Dornbusch, 1976), international asset pricing models (Merton, 1973; Solnik, 1974), and new open economy macroeconomic models (Obstfeld and Rogoff, 1995), PPP postulates that exchange rates adjust in the long run to price differentials in open economies to restore international commodity market equilibrium. A relatively extensive literature exists that examines the empirical validity of the PPP condition, mainly over the post-Bretton Woods system of floating nominal exchange rates. The empirical evidence, however, is rather mixed, and varies depending upon the time period, the countries and the econometric methodology. For a detailed overview see, for example, the recent survey studies by Rogoff (1996), Sarno and Taylor (2002), and Taylor and Taylor (2004).

Most empirical work centers on tests for a unit root in the real exchange rate or for cointegration between domestic and foreign prices and the nominal exchange rate. For instance, early studies, such as Adler and Lehmann (1983), Huizinga (1987), Edison (1987), and Corbae and Ouliaris (1988) find that the real exchange rate does not exhibit a stationary process. In contrast, Kim (1990), Glen (1992), Grilli and Kaminsky (1991), Lothian and Taylor (1996), Kuo and Mikkola (1999), and Chen and Wu (2000), using long time periods, find that real exchange rate reverts to its mean (although with a high degree of persistence) and follows a stationary process. The search for cointegration between the nominal exchange rate and domestic and foreign prices, although more limited, also provides conflicting evidence (e.g., Taylor, 1988; Mark, 1990; Layton and Stark, 1990; Cheung and Lai, 1993; Ender and Falk, 1998; and Coakley 
and Fuertes, 2000). Recent advances in panel econometrics (e.g., Papell, 1997; Frankel and Rose, 1996; Pedroni, 1995, 2001; Lothian, 1997; MacDonald, 1996; Wu and Chen, 1999; and Taylor and Sarno, 1998), nonlinear dynamics (e.g., Holmes and Maghrebi, 2004; Baum, Barkoulas, and Caglayan, 2001; and Kilian and Taylor, 2003), and cross-sectional dependence (e.g., O’Connell, 1998; Harris, Leybourne, and McCabe, 2005; Chortareas and Kapetanios, 2009; and Snaith, 2012) find stronger evidence supporting PPP, though the empirical findings remain mixed.

In a path-breaking paper, Johansen and Juselius (1992) attribute the apparent failure of PPP to the lack of precise specification of the sampling distribution of the data. That is, the research generally neglects (i) the time-series properties of the data, (ii) the possible interactions between prices, interest rates, and exchange rates, and (iii) differences between short-run and long-run effects. In particular, using the methodology of multivariate cointegration developed by Johansen (1988, 1991), Johansen and Juselius (1992) find support for PPP using data for the UK, but only when uncovered interest rate parity (UIP) appears in the system. Since the seminal paper of Johansen and Juselius (1992), a growing recognition emerges that while PPP does not hold in isolation, a long-run stationary relationship can occur between the real exchange rate and interest rate differentials. Juselius (1995) uses the same framework to analyze the mechanisms explaining the inflationary effects transmitted from Germany to Denmark and finds that the link between the goods and asset markets, postulated by the combined relation of PPP and UIP, is crucial for a full understanding of the movements of exchange rates, prices, and interest rates. Juselius and MacDonald (2000, 2004) apply this methodology to investigate the international parity relationships between the US and Germany, and the US and Japan. They argue that the balance of payment constraint implies that the financing of any imbalance in the current account must come from the capital and financial account. Hunter (1992), Sjoo (1995), Pesaran, Shin, 
and Smith (2000), Miyakoshi (2004), Ozmen and Gokcan (2004), Caporale, Kalyvitis, and Pitts (2001), Camarero and Tamarit (1996), Hatzinikolaou and Polasek (2005), among others, provide further evidence that modeling the interactions between the PPP and UIP generates linear stationary relations.

We extend this burgeoning literature by examining the empirical validity of PPP through the interdependence of adjustments in the international asset and commodity markets using data from the UK and the Euro Area. More precisely, we investigate whether the PPP holds for the exchange rate between the UK ("foreign country") and Germany ("home country") when combined with UIP. We represent the Euro Area by Germany, since Germany is the largest economy within the European Union and the Euro Area, as well as one of the major trading partners of the UK. ${ }^{1}$ We employ the Johansen cointegration method, which provides a flexible class of statistical models that combine long-run cointegrating relationships and short-run dynamics. We use monthly data for the UK and Germany, spanning the period from the introduction of the euro in January 1999 through April 2011. Using this sample period includes the recent period of the global financial crisis originating from the collapse of the US housing market in 2007, we explore the stability of the "augmented" system where inflation differentials and interest rate differentials enter the long-run cointegrating relationships.

The econometric analysis receives motivation from at least two pragmatic considerations. First, Germany and the UK are members of the European Union, a custom union and a common market that eliminated most trade barriers and capital controls among its members. This, in turn, virtually removes a large number of impediments that can prevent PPP and UIP from holding.

\footnotetext{
${ }^{1}$ Germany and the UK form a most important trade relationship. In 2011, only the US surpassed Germany in UK exports and Germany did hold the position as the top trading partner for imports, accounting for $11.06 \%$ and $12.87 \%$ of the UK's primary exports and imports, respectively. In comparison, the US accounted for $14.71 \%$ and $9.74 \%$, respectively.
} 
Thus, intuitively, we expect PPP to hold the best between Germany and the UK. Historically, however, the UK resisted a deep involvement with the European Economic Community (EEC). The 1957 Treaty of Rome established the EEC, but the UK only joined in 1973. The European Monetary System (EMS), founded in 1979, created the Exchange Rate Mechanism (ERM), a fixed exchange rate arrangement designed to reduce exchange rate volatility and achieve monetary stability in preparation for the introduction of the euro. The UK left the ERM in 1992, showing its economic independence, freeing the pound from the ERM, and regaining control over its monetary policy and interest rates. Since then, the UK resisted rejoining any type of exchange rate regime with the Euro Area countries and joining in the adoption of the euro.

Second, an obvious and intense interest exists within Europe as to the nature of the links between the countries of the European Union. The recent literature on the "European" business cycle (e.g., Barrios, Brülhart, Elliott, and Sensier, 2003; Kontolemis and Samiei, 2000; Camacho, Perez-Quiros, and Saiz, 2008) suggests that the UK and the Euro Area do not exhibit converging and synchronous business cycles. Barrios, Brülhart, Elliott, and Sensier (2003) find that the UK business cycle remains persistently out of phase with that of the main Euro Area economies. Kontolemis and Samiei (2000) provide evidence that the UK business cycle achieves its relative independence from the Euro Area economies because of its independent monetary policy. Camacho, Perez-Quiros, and Saiz (2008) find that UK business cycles more closely match the business cycles of Canada and US than the business cycles of the Euro area countries. Moreover, they show that no evidence exists of a "European economy" that acts as an attractor to the other economies of the area.

Accordingly, in light of the historical developments of the economic and financial relations between the UK and the European Union, and the findings of diverging and asynchronous business cycles, the question of the current degree of economic integration 
between the UK and the Euro Area becomes important.

Empirical analysis and tests of PPP and UIP shed some light on this issue. The PPP and UIP conditions provide indicators of the degree of economic integration between economies. PPP measures integration of the commodity markets, whilst UIP measures financial integration, and the greater the economic integration across countries, the greater the likelihood that these conditions will receive empirical support.

Few empirical studies (Alquist and Chinn, 2002; Gadea, Montañés, and Reyes, 2004; Lopez and Papell, 2007) examine PPP within the Euro Area using "synthetic" euro data. ${ }^{2}$ Alquist and Chinn (2002) find that the real exchange rate is nonstationary, suggesting that PPP does not hold in the Euro Area. Gadea, Montañés, and Reyes (2004) find some support for PPP within the Euro Area after incorporating two structural breaks. Scant evidence of the validity of PPP between the Euro Area and other major economies exists. Lopez and Papell (2007) study the convergence to PPP in the Euro Area from 1973 to 2001 and find that PPP holds better within the Euro Area than between the Euro Area and other European countries. Chinn (2002), using data on the "synthetic" euro-dollar exchange rate for 1985 to 2001, rejects PPP, but documents a stable long-run relationship between the real euro-dollar rate, productivity differentials, and the real price of oil. Koedijk, Tims, and van Dijk (2004), in addition to examining the validity of PPP within the Euro Area, also use "synthetic" euro data to study the validity of PPP between the Euro Area and other major economies. They find that, with the exception of Switzerland, PPP does not hold. Manzur and Chan (2010), using data through April 2007, construct a measure of "pooled" inflation among the 12 Euro countries and use this measure to test, in a simple regression framework, the relative version of PPP for the euro against the currencies of Japan,

\footnotetext{
${ }^{2}$ The "synthetic" euro is an artificial exchange rate constructed as a geometrically weighted average of the exchange rates of individual EMU currencies prior to 1999 (Artis and Beyer, 2004).
} 
the UK, and the US. Their results provide weak support for PPP in the case of USD/Euro and $£ /$ Euro exchange rates, and rejects PPP for the Yen/Euro.

We organize the rest of this paper as follows. Section 2 discusses the economic model and the statistical restrictions implied by the PPP and UIP conditions. Section 3, after a brief description of the data, performs a comprehensive I(1) cointegrated vector autoregressive (VAR) analysis, discusses the long-run effects of the stochastic trends, and conducts a long-run impact analysis. Section 4 offers concluding remarks.

\section{The Economic Framework}

According to the PPP condition, the nominal exchange rate between currencies of two countries depends on the relative prices in home and foreign countries. In its simplest form, absolute PPP is defined as:

$$
S_{t}=P_{t} / P_{t}^{*}
$$

and deviations from PPP with continuous compounding are defined as:

$$
p p p_{t}=p_{t}-p_{t}^{*}-s_{t}
$$

where $p_{t}$ is the logarithm of the domestic price level $P_{t}, p_{t}^{*}$ is the logarithm of the foreign price level $P_{t}^{*}$, and $s_{t}$ denotes the logarithm of the exchange rate $S_{t}$ (measured as units of domestic currency per unit of foreign currency ). In empirical applications, we verify PPP if $p p p_{t}$ is stationary.

According to the UIP condition, the interest rate differential between two countries equals the expected change in the exchange rate. In its simplest form, the UIP condition is defined as follows:

$$
E_{t}\left(\Delta s_{t+1}\right)=i_{t}-i_{t}^{*}
$$


where $\Delta$ is the first-difference operator, $E_{t}$ denotes the conditional expectation operator at time $t$ based on information available at time $t-1, E_{t}\left(\Delta s_{t+1}\right)$ equals the expected depreciation rate of the nominal exchange rate from period $t$ to $t+1, i_{t}$ is the domestic interest rate, and $i_{t}^{*}$ is the foreign interest rate . Logarithmic differencing equation (1) and applying the expectation operator gives:

$$
E_{t}\left(\Delta s_{t+1}\right)=E_{t}\left(\Delta p_{t+1}\right)-E_{t}\left(\Delta p_{t+1}^{*}\right),
$$

which gives relative PPP.

Substituting equation (4) into equation (3) and rearranging terms yields:

$$
i_{t}-i_{t}^{*}-E_{t}\left(\Delta p_{t+1}\right)+E_{t}\left(\Delta p_{t+1}^{*}\right)=0 .
$$

Under the assumption of rational expectations, where agents do not make systematic forecast errors in inflation rates, then

$$
E_{t}\left(\Delta p_{t+1}-\Delta p_{t+1}^{*}\right)=\Delta p_{t}-\Delta p_{t}^{*}+v_{t},
$$

where $v_{t}$ denotes an unpredictable i.i.d. shock. Then, combining equations (5) and (6) leads to

$$
i_{t}-i_{t}^{*}-\Delta p_{t}+\Delta p_{t}^{*}=v_{t}
$$

and testing for the UIP condition amounts to testing whether $v_{t}$ is stationary.

Following Juselius (1995) and Juselius and MacDonald (2000, 2004), we write a relation that combines the PPP and the UIP as follows:

$$
\left(i_{t}-i_{t}^{*}\right)=\left(\Delta p_{t}-\Delta p_{t}^{*}\right)+p p p_{t}+v_{t} .
$$

It follows that the PPP and UIP conditions hold jointly if $\left(i_{t}-i_{t}^{*}\right)-\left(\Delta p_{t}-\Delta p_{t}^{*}\right)-p p p_{t}$ is stationary. This can occur either if jointly $i_{t}-i_{t}^{*} \sim \mathrm{I}(0), \Delta p_{t}-\Delta p_{t}^{*} \sim \mathrm{I}(0)$, and $p p p_{t} \sim \mathrm{I}(0)$ or if $i_{t}-i_{t}^{*} \sim \mathrm{I}(1), \quad \Delta p_{t}-\Delta p_{t}^{*} \sim \mathrm{I}(1), \quad$ and $\quad p p p_{t} \sim \mathrm{I}(1), \quad$ but $\quad$ their linear combination 
$\left(i_{t}-i_{t}^{*}\right)-\left(\Delta p_{t}-\Delta p_{t}^{*}\right)-p p p_{t} \sim \mathrm{I}(0)$. In the first case, the PPP and UIP conditions hold independently of each other; in the second case, instead, they do not hold individually, but do hold together. That is, the nonstationarity of the PPP condition associates with the nonstationarity of the UIP condition to produce a stationary relation. We can also interpret equation (8) as follows: the nonstationarity of inflation differentials and interest rate differentials removes the nonstationarity of $p p p_{t}$ (i.e., the movements in inflation differentials, interest rate differentials, or both, compensate deviations from PPP).

Equation (8) defines a stationary equilibrium relation where interest rates and inflation rates pull the system together whenever the economy pushes $p p p_{t}$ away from equilibrium. A more flexible formulation, which relaxes the rational expectations hypothesis and acknowledges the weak correspondence between theoretical and observed variables and the effect of temporal aggregation (Juselius, 1995), leads to equation (9):

$$
\omega_{1}\left(i_{t}-i_{t}^{*}\right)-\omega_{2}\left(\Delta p_{t}-\Delta p_{t}^{*}\right)-\omega_{3} p p p_{t} \sim \mathrm{I}(0)
$$

where $\omega_{1}, \omega_{2}$, and $\omega_{3}$ are weights on PPP and UIP, which depend on the underlying structural parameters. The stationarity of the PPP and UIP conditions emerge as a special case of equation (9) when we set $\omega_{1}$ and $\omega_{2}$ equal to zero and set $\omega_{3}$ equal to one, or we set $\omega_{3}$ equal to zero and set $\omega_{1}$ and $\omega_{2}$ equal to one, respectively. Other special cases of equation (9) define stationary equilibrium relations, where either (i) $\omega_{1}\left(i_{t}-i_{t}^{*}\right)-\omega_{3} p p p_{t} \sim \mathrm{I}(0)$ and $\omega_{2}=0$ or (ii) $-\omega_{2}\left(\Delta p_{t}-\Delta p_{t}^{*}\right)-\omega_{3} p p p_{t} \sim \mathrm{I}(0)$ and $\omega_{1}=0$. In case (i), interest rates pull the system whenever the economy pushes $\mathrm{ppp}_{t}$ away from equilibrium; while in case (ii), inflation rates pull the system together whenever the economy pushes $p p p_{t}$ away from equilibrium. 
Juselius (1995) and Juselius and MacDonald (2000, 2004) emphasize case (i). They argue that models of exchange rate determination pertaining to these economies must jointly consider the deviations from PPP and UIP parities to induce stationarity by including the interaction of goods and capital markets. Pedersen (2002a, 2002b), on the other hand, proposes case (ii), which he calls "PPP with adjustment". That is, he argues, based on Gregory, et al. (1993) and Gregory (1994) that deviations from $p p p_{t}$ will adjust back to equilibrium, but not without adjustment costs. Specifically, PPP with adjustment holds, which Pederson (2002b) writes as "Definition 3" , when two I(2) price levels exhibit the following relationship (in our notation): $p p p_{t}+k_{1} \Delta p_{t}+k_{2} \Delta p_{t}^{*} \sim \mathrm{I}(0)$ and $k_{1} \neq 0, k_{2} \neq 0, k_{1} \neq k_{2}$. This relationship assumes asymmetric adjustment costs, and can be extended to include the case of symmetric adjustment costs: $p p p_{t}+k\left(\Delta p_{t}-\Delta p_{t}^{*}\right) \sim \mathrm{I}(0), k \neq 0$.In such a case, the inflation rate differential represents the adjustment costs. Deviations from ${ } p p_{t}$ indicate the degree of market integration. For perfect integration, $p p p_{t}$ equals one. Less than perfect integration leaves $p p p_{t}$ different from one. If so, then the cost of adjusting back to perfect integration depends on the inflation rate differential.

\section{The Empirical Analysis}

\subsection{The data and their univariate properties}

The empirical analysis uses monthly data for Germany and the UK over the period January 1999 to April 2011 (148 observations). The variables used in the analysis are defined as follows: $\Delta p_{t}=$ the German inflation rate, $\Delta p_{t}^{*}=$ the UK inflation rate, $i_{t}=$ the German 10-year constant maturity bond yield, $i_{t}^{*}=$ the UK 10 -year constant maturity bond yield, $p p p_{t}=p_{t}-p_{t}^{*}-s_{t}$ where $p_{t}=$ the $\log$ of the German price index, $p_{t}^{*}=$ the log of the UK price index, $s_{t}=$ the log of the nominal exchange rate, defined as Euro/£. The price indices are the harmonized indices of consumer 
prices (HCPI), 2005=100, and are not seasonally adjusted. We compute the rates of inflation as the logarithmic first difference of consumer prices. Data on exchange rate and price indices come from the statistical database of the European Central Bank (sdw.ecb.europa.eu), while data on bond yields come from the OECD Main Economic Indicators database (stats.oecd.org). We convert annual interest rates to monthly rates and divide by 100 to make the estimates comparable with logarithmic monthly changes. For similar reasons, we divide the $p p p_{t}$ series by 100. Since $p p p_{t}$ is the negative of the natural logarithm of the real exchange rate, a positive trend in $p p p_{t}$ means a real appreciation of the euro, although a rise in the exchange rate series means a nominal depreciation of the euro.

The Johansen cointegration procedure requires nonstationary variables. We ascertain the order of integration of each of the five series and their first differences using the standard Augmented Dickey-Fuller (ADF) and the more efficient Dickey-Fuller-Generalized Least Squares (DF-GLS) tests. Dickey and Fuller (1979) and Elliott, Rothenberg, and Stock (1996) present the details of these tests. The DF-GLS test procedure applies the DF test to locally demeaned (or demeaned and detrended) series and generally exhibits higher power than the standard ADF unit-root test. We choose the lag length of the ADF and DF-GLS tests using the Akaike information criterion (AIC) with an upper bound of 13 lags. We include a constant but no deterministic time trends. The inclusion of a linear trend proves insignificant and does not modify the main results in any substantial manner. The results of both the ADF and DF-GLS tests, reported in Tables 1 and 2, do not reject nonstationarity for all series using the 5-percent level. Strong evidence exists that all series possess a unit root or are I(1) processes (i.e., 
nonstationary in levels, but stationary in first differences). ${ }^{3}$ Many other studies contain the finding of a unit root in inflation rates (e.g., Rapach, 2003; Banerjee, Cockerell, and Russel, 2001). Based upon these findings, we test for unit roots in inflation differentials $\left(\Delta p_{t}-\Delta p_{t}^{*}\right)$, interest rate differentials $\left(i_{t}-i_{t}^{*}\right)$, German $\left(i_{t}-\Delta p_{t}\right)$ and $\mathrm{UK}\left(i_{t}^{*}-\Delta p_{t}^{*}\right)$ real interest rates, and real interest rate spreads, $\left(i_{t}-\Delta p_{t}\right)-\left(i_{t}^{*}-\Delta p_{t}^{*}\right)$. Theory suggests stationarity of interest rate differentials (i.e., interest rate parity) and stationarity of real interest rate spreads (i.e., real interest rate parity). Tables 1 and 2 report that we cannot reject the null hypotheses of unit roots in these series using a 5-percent level.

Our empirical approach starts from a statistically well-specified five-dimensional unrestricted VAR model for the components of $x_{t}^{\prime}=\left[\Delta p_{t}, \Delta p_{t}^{*}, i_{t}, i_{t}^{*}, p p p_{t}\right] \sim \mathrm{I}(1)$, and then reduces this general statistical model by testing for various theoretical restrictions. That is, our modeling approach responds to the economic questions of interest by embedding the economic model within the statistical model and using strict statistical principles as criteria to determine the adequacy of various empirical models.

In any VAR framework, the chosen lag length can importantly affect the results, since all inferences in both the cointegration and common trends analysis depend on the number of lags specified. No definitive procedure exists for choosing the lag length. Standard criteria defined by the multivariate versions of the Akaike information criterion (AIC), the Bayesian information criterion (BIC), and the Hannan-Quinn (H-Q) criterion suggest a lag length of 2, given a maximum lag order of 4 . We cannot justify the $\operatorname{VAR}(2)$ specification, however, as diagnostic

\footnotetext{
${ }^{3}$ Since the power of univariate unit-root tests is notoriously low, we also conducted a series of panel unit-root tests. The Levin, Lin, and Chu test statistic equal 0.796 ( $p$-value $=0.787$ ), the Breitung test statistic equals -1.046 ( $p$-value $=0.147)$, and the Fisher Chi-square $(\mathrm{ADF})$ statistic equals 9.814 ( $p$-value $=0.456)$, while the Choi Z-statistic $(\mathrm{ADF})$ equals $-0.294(p$-value $=0.384)$. The first two tests assume a common unit-root process, while the last two tests assume individual unit-root processes.
} 
tests suggest residual serial correlation. Consequently, we specify a VAR(3) model, using a number of specification tests. ${ }^{4}$

A further issue concerns the appropriate treatment of deterministic components such as constant and trend term (i.e., whether deterministic variables should enter the cointegrating space or the short-run model). Different treatment of constant and trend terms in the analysis lead towards different critical values (Johansen, 1991; Johansen and Juselius, 1990). We specify the model to include a restricted constant, following Johansen's (1995) suggestion that if the variables included in the system do not show growth, then the constant term should appear in the cointegrating space, implying that some equilibrium means in the cointegration space can differ from zero. We do not include a linear deterministic trend, since a trend is inconsistent with PPP (Papell and Theodoridis, 1998; Amara and Papell, 2006). Excluding a linear deterministic trend also proves consistent with the unit-root analysis.

We include three different types of dummy variables. First, we introduce centered seasonal dummy variables $D_{t}$ to account for seasonality in the data. Johansen (1996) proposes centered dummy variables, since they sum to zero over a year and are orthogonalized on the constant term. Second, we use a shift dummy variable $C_{2007: 10}$ to account for the developments of the global economic crisis. ${ }^{5}$ That is, $C_{2007: 10}$ equals 0 before October 2007 and 1 from October 2007 onward. We restrict this dummy variable to lie in the cointegration space to allow for the possibility that the global financial crisis of 2007 exerts a permanent effect on the mean of the cointegrating relations over the sample period. This issue is particularly relevant to our analysis

\footnotetext{
${ }^{4}$ This implies 2 lags of the first differences of the variables in the VEC model of the data.

${ }^{5}$ We assume that the break occurs in 2007:10 based on the visual inspection of the graphs combined with the institutional consideration about the beginning of the global recession and sub-prime crisis in the housing markets. We cannot verify, however, that the break really occurs at that time.
} 
since Stepthon and Larsen (1991) show that the cointegration tests may reflect sample dependency. Finally, we include an intervention dummy variable $D_{2008: 12}$ to account for a residual exceeding in absolute value $3 \sigma_{\varepsilon}$.

The final specification of the unrestricted VAR(3) model in error correction form is as follows:

$$
\begin{aligned}
& \Delta x_{t}=\Gamma_{1} \Delta x_{t-1}+\Gamma_{2} \Delta x_{t-2}+\alpha\left(\beta^{\prime} x_{t-1}+\rho_{0}+\rho_{1} C_{2007: 8}\right)+\phi_{o} D_{2008: 12}+\phi_{1} D_{t}+\varepsilon_{t}, \\
& \varepsilon_{t} \sim N_{p}(0, \Sigma), t=1, \ldots, T
\end{aligned}
$$

where $\left(\Gamma_{1}, \Gamma_{2}, \alpha, \beta, \rho_{0}, \rho_{1}, \Sigma\right)$ are unrestricted, $\Delta x_{t}^{\prime}=\left[\Delta^{2} p_{t}, \Delta^{2} p_{t}^{*}, \Delta i_{t}, \Delta i_{t}^{*}, \Delta p p p_{t}\right], \quad \rho_{0}$ is the constant restricted to the cointegration space, and $\rho_{1}$ is the coefficient of the shift dummy variable. The model in equation (10) is greatly overparameterized, but represents the starting point from which we test the various structural hypotheses (such as rank restrictions and linear parameter restrictions) extracted from economic theory. We perform cointegration analysis and related calculations and graphs using CATS in RATS, version 2 detailed in Dennis, Hansen, Johansen, and Juselius (2006).

\subsection{Specification tests}

This section summarizes the results from a battery of diagnostic tests recommended in Johansen and Juselius (1990, 1992) and Juselius (2006) applied to the residuals of equation (10). . Although the estimated coefficients of Equation (10) do not necessarily conform to economic interpretations, the unrestricted VAR provides the starting point from which a more parsimonious and economically meaningful representation can emerge. We must adequately specify the residual structure of the unrestricted VAR(3), however, prior to the determination of the cointegration rank and prior to the imposition of coefficient restrictions that emerge from a 
series of formal hypothesis tests. We make this assessment using the array of multivariate and univariate tests for serial correlation, autoregressive conditional heteroskedasticity (ARCH), and normality reported in Table 3.

The results of the multivariate Lagrange Multiplier (LM) test (Hosking, 1980) as implemented in Johansen (1995) indicate that we cannot reject the null hypotheses of no firstand second-order autocorrelation at the 1- and 5-percent significance levels, respectively.

The multivariate and univariate normality tests (Doornik and Hansen, 2008; Ljung and Box, 1978) look for skewness and kurtosis. We cannot reject the hypothesis of normality both in the multivariate case and the univariate case at any conventional level in all cases, except the univariate test of $p p p_{t}$, where we cannot reject at the 5-percent level. This is an important finding, since the properties of the cointegration estimators are sensitive to deviations from normality, especially deviations due to skewness.

The evidence from the multivariate ARCH tests (Duchesne and Lalancette, 2003; Hacker and Abdulnasser, 2005) suggests some problems with conditional heteroskedasticity. The univariate tests (Engle, 1988), however, show no signs of ARCH effects at the 10-percent level. Table 3 also reports the $R^{2}$ statistic, which measures the improvement in the explanatory power of the model compared to the random walk hypothesis. The model better explains changes in inflation rates than changes in interest rates and $\mathrm{ppp}_{t}$.

Figures 1 to 5 plot the actual and fitted values, the standardized residuals, the histogram of the standardized residuals with a superimposed histogram of the standardized normal distribution, and the correlogram for lags from 1 to 36. The graphical analysis suggests that the model exhibits well-behaved standardized residuals. We, therefore, conclude that the unrestricted VAR(3) model with a restricted constant, a shift dummy variable, an intervention dummy 
variable, and centered seasonal dummy variables provides satisfactory diagnostic results as a whole. Thus, we use this model for the I(1) cointegration analysis.

\subsection{Determination of the cointegrating rank: the trace test}

Johansen (1988) shows that the existence of cointegrating vectors implies that the system exhibits reduced rank. The cointegrating rank divides the data into $r$ linearly independent cointegrating relationships and $p-r$ common stochastic trends. We can interpret the cointegrating relationships as pulling the system through an adjustment process to long-run equilibrium. We can interpret the common trends, on the other hand, as the components of the system that push the process. Consequently, the cointegration rank proves crucial to the analysis, and affects all remaining inferences. Since distinguishing between stationary and nonstationary components proves difficult, Juselius (2006) suggests several formal and informal procedures to determine the rank. They include (a) the trace test, (b) the modulus of the roots of the companion matrix, (c) the graphical visualization of the recursively calculated trace test statistics, and (d) the graphical inspection of the stationarity of the cointegrating relations.

The trace test uses the likelihood ratio principle and tests the null hypothesis that at most r cointegration vectors exist against a general (unrestricted) alternative hypothesis that more than r cointegration vectors exist. The trace statistic is calculated as follows:

$$
Q_{r}=-T \sum_{i=r+1}^{p} \ln \left(1-\hat{\lambda}_{i}\right)
$$

where $T$ is the sample size, $p$ is the dimension of the vector, and $\hat{\lambda}_{r+1}, \ldots, \lambda_{p}$ are the ordered eigenvectors obtained from the generalized eigenvalue problem as described in Johansen and Juselius (1990).

Although the trace statistic $Q_{r}$ exhibits a nonstandard distribution, Johansen (1988, 
1995) and Osterwald-Lenum (1992), among others report asymptotic critical values. Two problems exist with these critical values. First, the asymptotic distribution of $Q_{r}$ with a small sample size provides a generally poor approximation of the true distribution. Juselius (2006) shows that in such case the test experiences substantial size and power distortions. To address this problem, we use the Bartlett small sample correction (Bartlett, 1937) of the trace test due to Johansen (2002). Second, Nielsen (2004) shows that the number and location of shift dummy variables affect the asymptotic distribution of the test, and as a result, we cannot use the conventional critical values to determine the cointegration rank. To address this second problem, we simulate new asymptotic critical values using the simulation program in CATS in RATS version 2 with 1000 random walks and 10,000 replications.

Table 4 provides trace test evidence for rank determination. We report the estimated eigenvalues, the trace statistics $Q_{r}$, the Bartlett corrected trace statistic $Q_{r}^{*}$ and the simulated $95 \%$ quantile $C_{0.95 \%}^{D}$, taking into account the presence of the shift dummy variable and the $p$ values for $Q_{r}$ and $Q_{r}^{*}$ (p-value and $p$-value*, respectively). Two points are noteworthy: (i) the Bartlett correction lowers the trace test statistic, and, (ii) $C_{0.95 \%}^{D}$ is lower than $C_{0.95 \%}$, which does not account for the shift dummy variable. ${ }^{6}$

\footnotetext{
${ }^{6}$ To check the robustness of this result, we compute the trace test statistic excluding the last part of the sample, which includes the period of the financial crisis. We construct two sub-samples. The first uses the Lehman Brothers bankruptcy of September 2008 as the ending date of the sub-sample, while the second uses the beginning of the subprime crisis of October 2007 as the ending date of the sub-sample. The finding of cointegration rank $r=2$ continues to hold in both cases. We also computed the trace test statistic excluding the transition period of the euro (January 1999-December 2001). The finding of cointegration rank $r=2$ holds, once again. Therefore, the implications of our analysis do not hinge on the presence of the crisis data in the sample nor on the data of the of the transition period. The details are available from the authors. We also compute the trace test using a different model specification that excludes all deterministic terms except the centered seasonal dummy variables. The test results overwhelmingly favor the choice of $r=2$, with a $p$-value of about 0.8 .
} 
The first two estimated eigenvalues appear to differ from zero. ${ }^{7}$ A substantial gap also exists between the second and the third eigenvalue, which points to a cointegrating rank of two. The trace test $Q_{r}$ and the Bartlett small-sample adjusted trace test $Q_{r}^{*}$ compared with the simulated $C_{0.95 \%}^{D}$ confirm this conjecture. The tests reject the nulls of zero and one cointegrating rank. In contrast, the trace test and the Bartlett small-sample adjusted trace test cannot reject the null of $r=2$ cointegrating relationships and, therefore, $p-r=3$ common trends in the model. Rejecting the hypothesis that $r=1$ runs counter to the frequent use of single equation models in the exchange rate determination literature. That is, a single equation model implies just one long-run cointegrating relationship between the relevant variables, whereas concluding that $r=2$ means that existing data require a more complex model. ${ }^{8}$

\subsection{Further evidence for rank determination}

Determining the cointegrating rank possibly proves as one of the most difficult tasks in empirical work using non-stationary data. ${ }^{9}$ Juselius (2006) strongly cautions against the exclusive dependence on trace-test evidence, as the LR tests may possess low power when the eigenvalue comes close to the non-stationary boundary. Hence, we should make use of as much additional information as possible for this purpose, as discussed by Juselius (2006). In this section, following Juselius (2006), we consider additional rank-relevant evidence, including the modulus of the characteristic roots of the model, the recursive graphs of the trace statistic, and the graphs of the cointegrating relations.

The calculus of the roots of the companion matrix complements the information of the

\footnotetext{
7 This conclusion is only tentative because of the unknown sampling distribution of the eigenvalues, which precludes testing whether eigenvalues significantly differ from one.

${ }^{8}$ The presence of multiple cointegration vectors indicates that an equilibrium sub-space exists rather than a unique equilibrium relationship to which the system adjusts. That means that the variables tie together in different ways in the long-run.

${ }^{9}$ The choice of the appropriate rank is critical because all the subsequent results depend on that choice.
} 
rank test. Table 5 shows that for $r=2$, the modulus of the largest unrestricted root drops to 0.562. ${ }^{10}$ No root over 1 suggests that the model does not include any explosive root and that all the eigenvalues, apart from the imposed unit roots, distinctly differ from unity. The restriction $r$ $=2$ seems an appropriate choice of reduced rank for the error-correction term. This finding matches the results of the trace test, but is only indicative because the roots do not come with confidence bands.

The recursive trace estimation uses a forward procedure based on Hansen and Johansen (1999), which visually displays the progression of the long-term linkages among the variables in the cointegrating system, and examines the sample dependence of the estimated cointegrating rank. This, in turn, enables the investigation of the robustness of the results for different sample sizes. We estimate the parameters based on a subsample from $t=1, \ldots, T_{0}$. The recursive nature of the process involves adding one observation at a time to generate samples $t=1, \ldots, T_{0}+t$, where $t=1, \ldots, T-T_{0}$. Two different procedures exist, the $\mathrm{X}(\mathrm{t})$ - and $\mathrm{R} 1(\mathrm{t})$-forms. ${ }^{11}$ In the $\mathrm{X}(\mathrm{t})$ form, we re-estimate all the parameters during the recursions, while in the R1(t)-form, we only re-estimate the long-term parameters, holding the short-term estimates fixed.

Figure 6 shows the time series graph of the trace statistic derived from the recursive process, where the upper panel show the results in the $\mathrm{X}(\mathrm{t})$-form and the lower panel show the results in the $\mathrm{R} 1(\mathrm{t})$-form. Using an expanding window, ${ }^{12}$ we calculate the trace test statistic adding one observation at a time (Hansen and Johansen, 1999) and then divide the test statistics by its 5-percent critical value. Following Juselius (2006), if the cointegrating rank is $r<p$, then

\footnotetext{
${ }^{10}$ If we impose $r=3$ when the appropriate rank is $r=2$, then the third root comes closer to unity, and we should reduce $r$ from 3 to 2. When $r=2$, we observe the lowest first root beyond the unit root is 0.562. See Juselius (2006).

${ }^{11}$ By fixing the estimates of the short-run parameters, we reduce the variance of the long-run parameters, which is the primary interest of cointegration analysis (Hansen and Johansen, 1999). This motivates the R1(t)-form.

${ }^{12}$ We fix the base period, January 1999 to December 2002, at about 35 percent of the sample, following the suggestion of Brüggemann, Donati, and Warne (2003).
} 
the recursively calculated trace statistics for $j=1, \ldots, r$ should display a value above one throughout the sample and grow linearly but shall stay constant for $j=r+1, \ldots, p$. As both panels of Figure 14 reveal, the recursively calculated trace statistics exhibit a linear growth for $j=1$ and 2 , but no growth for $j=3,4$, and 5 . The first two linearly growing trace statistics correspond to two cointegration relations, which supports the choice of $r=2$, while the remaining three relations indicate small eigenvalues, which correspond to a unit root or near-unit root.

Finally, we inspect the graphs of the five cointegrating relationships for evidence of stationarity. In our case, the first two relations appear stationary, and the remaining three do not. Such evidence supports the choice of rank $r=2$ (Juselius, 2006). Figures 7 through 11 graph the individual cointegrating relationships of the unrestricted model. The upper panel of each graph shows the given cointegration relation based on the $\mathrm{X}(\mathrm{t})$-form and the lower panel shows the same relationship based on the R1(t)-form. The order of cointegration is that of decreasing stationarity. We also notice that no trend exists in the first and second cointegrating relationships, as neither interest rates, $p p p_{t}$, nor inflation rates should contain a deterministic trend, and their variance suggests stability over the sample period. The graphs of the third, fourth, and fifth relationships show a persistent behavior and do not suggest mean-reverting dynamics. On the other hand, the graphs of the first and second cointegrating relationships repeatedly cross the mean, which suggest stationarity, supporting the results of the trace tests.

The validity of our statistical inferences requires that no I(2) variables should enter the model. Juselius (2006) and Juselius and Toro (2005) suggest various criteria to investigate the presence of I(2) variables. First, they suggest comparing the trace test to the Bartlett corrected trace test. The ratio between $Q_{r}$ and $Q_{r}^{*}$ should fall between 1 and 1.2 and should not exceed 
1.5. Second, the first unrestricted root of the companion matrix should not jump up close to unity, which indicates the presence of I(2) variables in the system. Third, graphs of the X(t)-form and the R1(t)-form look different if the data contain some I(2) variables. Applying these criteria to the data shows that no I(2) trends exist.

\subsection{Tests of parameter constancy}

A well-specified model exhibits parameter constancy. This proves particularly important during a financial crisis. Hansen and Johansen (1999) suggest applying a fluctuation test to the nonzero eigenvalues of the reduced-rank matrix. The test provides general information with regard to the constancy of the parameters because we can express the eigenvalues as quadratic functions of the $\alpha$ and $\beta$ parameters (Juselius, 2006). If both are constant, the eigenvalues will share this property. The fluctuation test rejects parameter constancy when the recursively calculated eigenvalues fluctuate excessively. We apply the test to the eigenvalues themselves, $\lambda_{i}$, and to the transformation $\xi=\log \left(\lambda_{i} /\left(1-\lambda_{i}\right)\right)$ to obtain a symmetrical representation of their limiting distribution. We can also jointly evaluate the constancy of the eigenvalues by considering the sum of the transformed eigenvalues.

Figure 12 reports the time path of the two largest eigenvalues with their 95-percent confidence bands computed using the Bartlett kernel estimator of the asymptotic variance. These two eigenvalues significantly differ from zero for the entire sample, reinforcing the evidence in favor of two cointegrating vectors. Figure 13 displays the time path of the transformed eigenvalues and their sum, while Figure 14 presents the corresponding fluctuation tests. In the R1(t)-form, we do not reject the constancy of $\xi_{1}, \xi_{2}$, and their sum because the test statistic falls below the 5-percent critical value. Conversely, the test in the X(t)-form reject the constancy of $\xi_{1}, \xi_{2}$, and their sum due to the fluctuations in the beginning of the recursion. We can ascribe 
this outcome, however, to the small sample size (Juselius, 2006) or, more importantly, to the euro transition period. ${ }^{13}$

We further investigate whether any significant structural break exists in the cointegration vectors using two additional recursively calculated tests developed by Hansen and Johansen (1999): the test for the constancy of $\beta$ and the test for the constancy of the log-likelihood function.

The test for the constancy of $\beta$ investigates parameter constancy of the cointegration space. The null hypothesis of the test states that the cointegration vectors estimated over the full sample do not differ from the cointegration vectors estimated recursively. The test statistic is asymptotically distributed as chi square with $(p-r) \times r$ degrees of freedom. Under the null hypothesis of constancy of $\beta$, the 95-percent quantile of the test is 18.3 .

The test for the constancy of the log-likelihood function investigates parameter constancy of the model. The test is similar to the recursive Chow test used in single equation models (Juselius, 2006). Under the null hypothesis of constant parameters, the 95-percent quantile of the test is 1.36 . Figures 15 and 16 illustrate the test results. Figure 15 shows that stability of $\beta$ may not exist for the $\mathrm{X}(\mathrm{t})$-form, but does exist for the $\mathrm{R} 1(\mathrm{t})$ form. Instability in the $\mathrm{X}(\mathrm{t})$-form, however, occurs mainly at the beginning of the recursion and for a brief period of time in the first quarter of 2005, which coincides with the start of the low interest rate policy of the European Central Bank and the weakening of the euro against the pound, and in the middle of 2008, which approximately corresponds to the beginning of the global financial crisis. Juselius (2006) recommends placing more reliance on the R1(t)-form plot, and, based on these

\footnotetext{
${ }^{13}$ During the transition period, which lasts from January 1999 to December 2001, transactions in the countries of the euro area could use both the euro and national currencies. During this transition period, the euro only serves an accounting unit, and euro notes and coins only start circulating in January 2002, when countries withdraw their national currencies from circulation.
} 
considerations, we find evidence that suggests relatively stable parameters of the cointegration space. Similar conclusions emerge by considering the time path of the log-likelihood function in Figure 16.

\subsection{Tests of long-run exclusion and long-run weak exogeneity.}

This subsection tests for long-run exclusion and weak exogeneity, ${ }^{14}$ which provides useful information on the relevance and the differential role of the variables in the cointegrating space.

Long-run exclusion tests investigate whether we can exclude any variables from the cointegration space. We formulate the tests as a zero row in the $\beta$-matrix (i.e., $\beta_{i j}=0, j=1, \ldots$, $r$ ). Table 6, Panel A, reports the test statistics, asymptotically distributed as $\chi^{2}(r),{ }^{15}$ which show that for $r=2$, we cannot exclude any of the variables, including the shift dummy $C_{2007: 10}$ and the constant. This important result signifies that all the variables participate in the cointegration space and enter the long-run relationships. The significance of the restricted shift dummy variable is of particular interest, since it accounts for a change in the equilibrium means of the cointegrating relations in 2007:10, associated with the recent financial crisis.

Tests for weak exogeneity examine whether leading or driving forces exist in the systems in the long-run. A variable exhibits weak exogeneity when it significantly influences the remaining variables in the error-correction process, but is not significantly affected by those other variables in the long-run adjustment process. In other words, a weakly exogenous variable dominates and plays a leading role in the system. We formulate these tests as a zero row in the $\alpha$-matrix (i.e., $\alpha_{i j}=0, j=1, \ldots, r$ ). This means that a variable does not respond to any of the (long-run) error-correction terms and, thus, we consider it as weakly exogenous with respect to

\footnotetext{
${ }^{14}$ Juselius (2006) discusses these tests in detail.

${ }^{15}$ Whereas likelihood ratio testing for cointegrating rank leads to a nonstandard inference situation, conditional likelihood ratio testing, for a given cointegrating rank, produces standard asymptotically chi-squared test statistics.
} 
the long-run parameters $\beta^{\prime}$. If we do not reject the null hypothesis, then we can say that the variable in question "drives" (common stochastic trend) the system: it "pushes" the system, but it is not "pushed" by it. It also means that the sum of the cumulated empirical shocks to the variable in question defines one common driving trend. Table 6 reports the likelihood ratio test statistics, asymptotically distributed as $\chi^{2}(r)$. For $r=2$, we reject the weak exogeneity hypothesis for the UK and the German inflation rates at any conventional level. We fail to reject, however, the hypothesis for the PPP condition $(p$-value $=0.211)$, the UK interest rate $i_{t}^{*}(p$-value $=0.138$ ), and the German interest rate $i_{t}(p$-value $=0.062)$, although the latter case is borderline. Considering the German interest rate weakly exogenous, however, proves consistent with the choice of the rank $r=2$. These findings are quite similar to the findings in Juselius and MacDonald (2000, 2004): inflation rates adjust to interest rates and the real exchange rate and not vice versa. As emphasized by Juselius and MacDonald (2004), this empirical result contradicts the predictions of models of exchange rate dynamics built on rational expectations and UIP, and in particular provides evidence against the Fisher hypothesis in open economies. We can justify this result, however, by appealing to the "imperfect knowledge economics" approach developed by Frydman and Goldberg (2003, 2006), which shows that under imperfect information expectations, exchange rates fluctuations do not represent movements toward a fundamental purchasing power equilibrium, but movements generated by traders' behavior in the foreign exchange market (Juselius and MacDonald, 2004).

\subsection{Linear restrictions on the cointegration space}

This subsection explores the existence of valid restrictions on the cointegration space in the I(1) 
cointegrated VAR(3) model under the restriction of two cointegrating vectors. ${ }^{16}$ The tests include the shift dummy variable $C_{2007: 10}$, and the restricted constant. Table 7 enumerates the test results. ${ }^{17}$ First, we report test results for the stationarity of $\operatorname{ppp}_{t}\left(H_{1}\right)$, the inflation differentials $\left(H_{2}\right)$, the interest rate differentials $\left(H_{3}\right)$, and the real interest rate in Germany and the UK $\left(H_{4}\right.$ and $H_{5}$, respectively). We find evidence of stationarity only for the inflation differentials, (although the $p$-value is not very high) when the rest of the cointegrating vectors remain unrestricted. The stationarity of inflation differentials, however, is somewhat ambiguous, since the unit-root tests refute stationarity. Next, we report test results for the stationarity of the real interest rate differentials, imposing $\left(H_{6}\right)$ and not imposing $\left(H_{7}\right.$ and $\left.H_{8}\right)$ the full proportionality restrictions. We fail to find evidence of stationarity except, marginally, for $H_{7}$. We then test if inflation differentials $\left(H_{9}\right)$, the interest rate differentials $\left(H_{10}\right)$, the real interest rates in Germany and the UK ( $H_{11}$ and $H_{12}$, respectively), and the Fisher parity conditions $\left(H_{13}\right)$ combine with $p p p_{t}$ to produce linear stationary relationships. We find evidence of stationarity only when we combine the inflation rate differentials with $p p p_{t}$. We, therefore, identify the first cointegration vector where $\operatorname{ppp}_{t}\left(H_{1}\right)$ and the inflation differentials $\left(H_{2}\right)$ cointegrate. That is,

$$
\left(\Delta p_{t}-\Delta p_{t}^{*}\right)+0.502 p p p_{t}+0.001 C_{2007: 10}+0.002 \sim \mathrm{I}(0)
$$

In the long-run, inflation differentials link to deviations from PPP. Equation (12) clearly implies that although $p p p_{t}$ is not by itself a stationary process, it becomes stationary when combined

\footnotetext{
${ }^{16}$ The hypotheses are of the form $\beta=(H \phi, \psi)$ where $H$ is the design matrix, $\phi$ contains the restricted parameters, and $\psi$ is a vector of parameters that are freely estimated. For details see Juselius (2006).

${ }^{17}$ Since the rank equals two $(r=2)$, we can only test for cointegration, where theoretical relations restrict at least two of the parameters. This requirement is imposed by the degrees of freedom of the $\chi^{2}(v)$ distribution, which are calculated as $v=k-(r-1)$, where $k$ is the number of restrictions (Juselius, 2006).
} 
with the inflation rate differentials. ${ }^{18}$ We note that PPP in conjunction with unrestricted inflation rates $\left(H_{14}\right)$ also yields a stationary outcome. This implies non-symmetric adjustment costs. The p-value associated with $H_{14}$, however, is lower than the $p$-value associated with $H_{9}$ and a LR test $\left(\chi^{2}(1)=1.14, p\right.$-value $\left.=0.285\right)$ confirms the validity of the symmetry restriction. ${ }^{19}$ The coefficient on $p p p_{t}$ implies that a 1-percent change in $p p p_{t}$ leads, in the long-run, to approximately 0.5-percent cost of adjustment in the inflation rate differentials. We do not find, however, evidence of stationarity when we combine the interest rate differentials with $p p p_{t}$. These results strikingly differ from those of Johansen and Juselius (1992), Juselius (1995), and Juselius and MacDonald (2000, 2004), who finds that $p p p_{t}$ becomes stationary only when combined with the interest rate differential and conclude that capital markets and commodity markets are interdependent.

Finally, we find evidence of a stationary relation when we combine the inflation and interest rates in the Germany with the UK inflation rate $\left(H_{15}\right)$. We therefore identify the second cointegration vector where the German interest rate cointegrates with the inflation rates in Germany and the UK. That is,

$$
\left(i_{t}-\Delta p_{t}\right)+2.175 \Delta p_{t}^{*}-0.003 C_{2007: 10}-0.005 \sim \mathrm{I}(0)
$$

\footnotetext{
${ }^{18}$ This result questions the stationarity of the inflation rate differential $\left(\mathrm{H}_{2}\right)$. That is, if the inflation rate differential is really $\mathrm{I}(0)$, then it cannot cointegrate with $p p p_{t}$, which is $\mathrm{I}(1)$.

${ }^{19}$ For completeness, we also test, following Pedersen (2002b), for cointegration between $p_{p p} p_{t}$ and the rate of inflation of Germany or the UK separately, which implies that the adjustment costs are borne unilaterally by only one country. In each case, we reject the hypotheses that $p p p_{t}$ forms a stationary relation with the German inflation rate alone $\left(\chi^{2}(2)=11.739, p\right.$-value $\left.=0.003\right)$ or with the $\mathrm{UK}$ inflation rate alone ( $\chi^{2}(2)=5.264, p$-value $=0.072$ ) at the 5-percent level.
} 
A test of the joint stationarity of $H_{9}$ and $H_{15}$ yields a $\chi^{2}(4)$ statistic of 7.393 with an associated $p$-value of 0.1119 , which indicates that the two cointegrating relations span the entire cointegration space.

Tables 8, 9, and 10 report a structural representation of the cointegration space containing all the information included in the restrictions (i.e., the estimates of $\alpha, \beta$, and $\Pi$ matrices subject to the rank condition that $r=2$, with $\beta_{1}^{\prime}$ and $\beta_{2}^{\prime}$ normalized for $\Delta p_{t}$ and $\Delta p_{t}^{*}$, respectively, the structural restrictions defined by $H_{9}$ and $H_{15}$, and weak exogeneity ${ }^{20}$ ). Note that the joint estimation of the cointegrating vectors (i.e., the $\beta$ matrix) alters slightly the values of the unconstrained coefficients when compared to equations (12) and (13). The estimates of the $\alpha$ matrix suggest that the two cointegrating relations adjust significantly in the German and UK inflation rates. This conforms to the weak exogeneity of the German and UK inflation rates. The row of Table 10 gives the estimates of the combined effect of the two cointegrating relations. The German inflation rate exhibits significant responses to itself, the PPP condition, and the German interest rate. The UK inflation rate, on the other hand, exhibits significant responses to itself, the PPP condition, and the German interest rate. Juselius and MacDonald (2004) find what they call the "price puzzle effect” (i.e., inflation rates do not affect nominal interest rates, whereas nominal interest rates positively affect inflation rates). Our findings differ, in part, from Juselius and MacDonald (2004). We find that nominal interest rates exert a negative effect on inflation rates and the effect is limited to the German inflation rate. The UK interest rate does not affect inflation in Germany or the UK. Finally, we note that the shift dummy variable $C_{2007: 10}$ also exerts a significant effect on inflation rates.

\footnotetext{
${ }^{20}$ The unrestricted estimates of the $\alpha$ matrix, obtained without imposing the weak exogeneity restriction, are not significantly different from zero.
} 


\subsection{Analysis of the common stochastic trends}

In this section, we estimate the moving average representation of the cointegrated system in order to extract information about the nonstationary components that drive the system in the long run. The moving-average representation of equation (1) is given by:

$$
x_{t}=C \sum_{i=0}^{t}\left(\varepsilon_{i}+\Psi D_{i}\right)+C_{1}(L)\left(\varepsilon_{t}+\phi D_{i}\right)+x_{0}
$$

where $C=\beta_{\perp}\left(\alpha_{\perp}^{\prime} \Psi \beta_{\perp}\right)^{-1} \alpha^{\prime}=\beta_{\perp} \alpha_{\perp}^{\prime}$ equals the long-run impact matrix.

We report the common-trend representation corresponding to the restricted VAR model $(r=2)$ subject to the weak exogeneity conditions on $i_{t}, i_{t}^{*}$, and $p p p_{t}$ imposed on $\alpha$ and the restrictions imposed on $\beta$ by $H_{9}$ and $H_{15}$. By construction, the three common stochastic trends in the system equal the cumulated shocks of $i_{t}, i_{t}^{*}$, and $p p p_{t}$ (i.e., $\sum \varepsilon_{i_{t}}, \sum \varepsilon_{i_{t}^{*}}$, and $\sum \varepsilon_{p p p_{t}}$, respectively). Tables 11,12 , and 13 report the estimates of $\alpha_{\perp}$, the associated loadings (weights) $\beta_{\perp}$, and the estimates of the long-run impact matrix. Table 11 identifies each the three common trends.

Table 12 highlights the dynamics of the system. We observe that the first common trend, identified by the cumulated shocks of the German interest rate, affects the rates of inflation in Germany and in the UK (as well as itself). On the other hand, the second common trend, identified by the cumulated shock of the UK interest rate, affects only itself. Finally, the third common trend, identified by the cumulated shocks of $p p p_{t}$, affects both the inflation in Germany and the UK (as well as itself). Table 13 displays the long-run effects of a shock to the system. The significance of each element of the $C$ matrix provides an indication of the effect of a shock on each of the variables in the system. We note that the cumulative shocks to $\Delta p_{t}$ and $\Delta p_{t}^{*}$ are, 
by construction, equal to zero, since the UK and German inflation rates only adjust to the rest of the variables in the system. On the other hand, cumulative shocks to the German interest rate affect the UK and German inflation rates, in addition to itself. Similarly, shocks to the PPP condition significantly affect the UK and German inflation rates, in addition to itself. Shocks to the UK interest rate only affect itself.

\section{Conclusion}

This paper examines the empirical validity of the PPP hypothesis between the UK and the Euro Area, represented by Germany, the largest of its members. Following Juselius (1995) and Juselius and MacDonald (2000, 2004), we use the error-correction and moving-average representations of a five-dimensional VAR model, whose elements include the German and UK long term interest rates, the German and UK inflation rates, and the real exchange rate. The analysis uses monthly data from the introduction of the euro in January 1999 through April 2011.

The econometric analysis does not validate the linear restrictions implied by the Johansen and Juselius' (1992) original hypothesis, subsequently confirmed by Juselius (1995) and Juselius and MacDonald (2000, 2004), among others. That is, these authors conclude that stationarity of $p p p_{t}$ occurs when we link PPP to UIP. We do not find that the nonstationarity of the PPP condition associates with the nonstationarity of the interest rates differentials to produce a stationary relation. This conclusion, although surprising, is not totally unexpected, given the historical resistance of the UK to engage in a deep financial integration and commitment with the European Union, and the diverging and asynchronous business cycles of the UK and the Euro Area.

On the other hand, we do not reject the PPP hypothesis. We find that two valid cointegrating relationships do exist. First, the PPP condition cointegrates with the inflation rates differentials. The Germany-UK PPP relation is not stationary by itself; but, stationarity emerges 
when we link PPP to the inflation rates of both countries. This weak support for PPP, however, provides encouragement, given that (i) the monthly frequency of the data does not favor PPP (Hakkio and Rush, 1991), which is a long-run phenomenon, and (ii) the sample includes the transition period of the introduction of the euro, which a variety of exogenous elements likely contaminates, ${ }^{21}$ and the global financial crisis, which prompts aggressive interest rate policies in the months following the collapse of Lehman Brothers. Second, the UK and German inflation rates cointegrate with the German interest rate. Pedersen (2002) defines PPP with adjustment and uses adjustment costs to develop his specification, where the inflation rate differential represents the adjustment cost. ${ }^{22}$ In any event, this empirical result contradicts the predictions of conventional monetary models of exchange rate dynamics built on rational expectations and interest rate parity.

Juselius and MacDonald (2000, 2004) find that long-term interest rates and the PPP condition encompass the weakly exogenous variables. Further, they find that the inflation rates do not drive the rest of the system, but rather respond to the variables in the rest of the system. We find similar results.

First, we find that the German and UK inflation rates exhibit equilibrium-adjusting behavior (i.e., they are "pulled” back to equilibrium when they are "pushed” away from it). The German and UK interest rates, as well as the PPP condition, on the other hand, are weakly exogenous to the system (i.e., they affect the stochastic behavior of the German and UK inflation rates without being affected by them).

\footnotetext{
${ }^{21}$ This argument is also made by Manzur and Chan (2010).

${ }^{22}$ We can also justify the empirical support of PPP induced by the nonstationarity of inflation differentials by appealing to models where foreign exchange traders' "imperfect information expectations” (Frydman and Goldberg, 2003, 2005) generate movements in exchange rates or models of firms in imperfectly competitive markets facing inflation costs (Bacchiocchi and Fanelli, 2005). See also Frydman, Goldberg, Johansen, and Juselius (2012) in relation to "imperfect information expectations."
} 
Second, we find that the system is "pushed" by three common trends, associated with the cumulated shocks to the German and UK interest rates and the PPP condition, with the first common trend, associated with the cumulated shocks of the German interest rate and third common trend, associated with the cumulated shock of the PPP condition playing a dominant role, as each drives themselves as well as the inflation rates in Germany and the UK, while the second common trend, associated with cumulated shocks of the UK interest rate, drives only itself. In this regard, we can say that Germany dominates the UK in the cointegrating relationship in that the UK interest rate does not drive any other variable, whereas the German interest rate drives both the German and UK inflation rates, perhaps reflecting the "safe haven" role of the

German financial markets in the European Union. A similar interpretation is suggested by Juselius and MacDonald (2004) in the context of the role of the dollar as world reserve currency.

\section{References:}

Adler, M., and Lehmann, B., 1983. Deviations from purchasing power parity in the long run. Journal of Finance 38 1471-1487.

Alquist, R and Chinn, M., 2002. The Euro and the productivity puzzle: An alternative interpretation. NBER Working Paper No. 8824.

Artis M., and Beyer, A., 2004. Issues in money demand. The case of Europe. Journal of Common Market Studies 42, 717-736.

Amara J., and Papell, D. H., 2006. Testing for purchasing power parity using stationary covariates. Applied Financial Economics 16, 29-39.

Bacchiocchi, E., and Fanelli, L., 2005. Testing the purchasing power parity through I(2) cointegration techniques. Journal of Applied Econometrics 20, 749-770.

Barrios, S., Brülhart, M., Elliott, R. J., and Sensier, M., 2003. A tale of two cycles: Cofluctuations between UK regions and the Euro zone. The Manchester School 71, 265292.

Bartlett, M. S., 1937. Properties of sufficiency and statistical tests. Proceedings of the Royal Statistical Society A 160, 268-282. 
Baum, C. F., Barkoulas, J. T., Caglayan, M., 2001. Nonlinear adjustment to purchasing power parity in the post-Bretton Woods era. Journal of International Money and Finance 20, 379- 399.

Banerjee, A., Cockerell, L., and Russel, B., 2001. An I(2) analysis of inflation and the markup. Journal of Applied Econometrics 16, 221-240.

Brüggemann, A., Donati, P., and Warne, A., 2003. Is the demand for Euro area M3 stable? European Central Bank Working Paper No. 255.

Camacho, M., Perez-Quiros, G., and Saiz, L., 2008. Do European business cycles look like one? Journal of Economic Dynamics and Control 32, 2165-2190,

Camarero M., and Tamarit, C., 1996. Cointegration and the PPP and the UIP hypotheses: An application to the Spanish integration in the EC. Open Economies Review 7, 61-76.

Caporale, G. M., Kalyvitis S., and Pittis, N., 2001. Testing for PPP and UIP in an FIML framework: Some evidence for Germany and Japan. Journal of Policy Modeling 23, 637650.

Chen, S., and Wu, J., 2000. A re-examination of purchasing power parity in Japan and Taiwan. Journal of Macroeconomics 22, 271-284.

Cheung, Y.-W., and Lai, K. S. , 1993. Long-run purchasing power parity during the recent float. Journal of International Economics 34, 181-192.

Chortareas, G., and Kapetanios, G., 2009. Getting PPP right: Identifying mean-reverting real exchange rates in panels. Journal of Banking and Finance 33, 390-404.

Corbae, P. D., and Ouliaris, S., 1988. Cointegration and tests of purchasing power parity. Review of Economics and Statistics 70, 508-511.

Coakley, J., and Fuertes, A. M., 1997. New panel unit root tests of PPP. Economics Letters 57, 17-22.

Dennis, J. G., Hansen, H., Johansen, S., and Juselius, K., 2006. CATS in RATS. Cointegration Analysis of Time Series, Version 2, Evanston, IL, Estima.

Dickey, D. A., and Fuller, W. A., 1979. Distribution of the estimators for autoregressive time series with a unit root. Journal of the American Statistical Association 74, 427-431.

Dornbusch, R., 1976. Expectations and exchange rate dynamics. Journal of Political Economy 84, 1161-1176.

Doornik, J. A., and Hansen, H., 2008. An omnibus test for univariate and multivariate normality. Oxford Bulletin of Economics and Statistics 70, 927-939. 
Duchesne, P., and Lalancette, S., 2003. On testing for multivariate arch effects in vector time series models. The Canadian Journal of Statistics 31, 275-292.

Edison, H. J., 1987. Purchasing power parity in the long run: A test of the dollar/pound exchange rate (1890-1978). Journal of Money, Credit and Banking 19, 376-387.

Elliott, G., Rothenberg, T. J., Stock, J. H., 1996. Efficient tests for an autoregressive unit root. Econometrica 64, 813-836.

Enders, W., and Falk, B,. 1998. Threshold autoregressive, median unbiased, and cointegration tests of purchasing power parity. International Journal of Forecasting 14, 171-186.

Engle, R., 1988. Autoregressive conditional heteroscedasticity with estimates of the variance of United Kingdom inflation. Econometrica 96, 893-920.

Frankel, J., and Rose, A., 1996. A panel project on purchasing power parity: Mean reversion within and between countries. Journal of International Economics 40, 209-224.

Frenkel, J., 1976. A monetary approach to the exchange rate: Doctrinal aspects and empirical evidence. Scandinavian Journal of Economics 76, 200-224.

Frydman, R., and Goldberg, M., 2003. Imperfect knowledge expectations, uncertainty adjusted UIP and exchange rate dynamics. In Aghion, P., Frydman, R., Stiglitz, J., and Woodford, M., (eds.). Knowledge, Information and Expectations in Modern Macroeconomics: In Honor of Edmund S. Phelps, Princeton, NJ: Princeton University Press.

Frydman, R., and Goldberg, M., 2006. Exchange Rates and Risk in a World of Imperfect Knowledge: A New Approach to Modeling Asset Markets. Princeton, NJ: Princeton University Press.

Frydman, R., Goldberg, M. D., Johansen, S., and Juselius, K., 2012. Long swings in currency markets: Imperfect knowledge and I(2) trends. Working Paper. http://www.econ.nyu.edu/user/frydmanr/long\%20swings_4\%203\%202012_fgjj.pdf

Gadea, M., Montañés, A., and Reyes, M., 2004. The European Union and the US dollar: From post-Bretton-Woods to the Euro. Journal of International Money and Finance 23, 11091136.

Glen, J., 1992. Real exchange rates in the short, medium, and long run. Journal of International Economics 33, 147-166.

Gregory, A. W., 1994. Testing for cointegration in linear quadratic models. Journal of Business and Economic Statistics 12, 347-360. 
Gregory, A. W., Pagan, A. R., and Smith, G. W., 1993. Estimating linear quadratic models with integrated processes. In: Phillips, P. C. B., (ed.), Models, Methods, and Applications of Econometrics: Essays in Honor of A.R. Bergstrom, Ch. 15. Cambridge, MA: Basil Blackwell.

Grilli, V., and Kaminsky, G. , 1991. Nominal exchange rate regimes and the real exchange rate: Evidence from the United States and Great Britain, 1985-1986, Journal of Monetary Economics 27, 191-212.

Hacker, R. S., and Abdulnasser H.-J, 2005. A test for multivariate ARCH effects. Applied Economics Letters 12, 411-417.

Hakkio, C. S. and Rush, M., 1991. Cointegration: How short is the long run?. Journal of International Money and Finance 10, 571-581.

Hansen, H., and Johansen, S., 1999. Some Tests for Parameter Constancy in Cointegrated VARModels. The Econometrics Journal 2, 306-333.

Harris, D., Leybourne, S., and McCabe, B., 2005. Panel stationarity tests for purchasing power parity with cross-sectional dependence. Journal of Business and Economic Statistics 23, 395-409.

Hatzinikolaou, D., and Polasek, M., 2005. The commodity-currency view of the Australian dollar: A multivariate cointegration approach. Journal of Applied Economics 8, 81-99.

Holmes, M. J., and Maghrebi, N., 2004. Asian real interest rates, non-linear dynamics and international parity. International Review of Economics and Finance 13, 387-405.

Hosking J. R. M., 1980. The multivariate portmanteau statistic. Journal of American Statistical Association 75, 602-607.

Huizinga, J., 1987. An empirical investigation of the long-run behavior of real exchange rates, In Brunner, K., and Meltzer, A., eds., Carnegie-Rochester Conference Series on Public Policy 27, 149-214.

Hunter, J., 1992. Tests of cointegrating exogeneity for PPP and uncovered interest rate parity for the UK. Journal of Policy Modeling, Special Issue: Cointegration, Exogeneity and Policy Analysis 14, 453-463.

Johansen, S., 1988. Statistical analysis of cointegration vectors. Journal of Economic Dynamics and Control 12, 231-254.

Johansen, S., 1991. Estimation and hypothesis testing of cointegration vectors in Gaussian vector autoregressive models. Econometrica 59, 1551-1580. 
Johansen, S., 1995. Likelihood-Based Inference in Cointegrated Vector Autoregressive Models. Oxford University Press, New York.

Johansen S., 2002. A small sample correction for the test of cointegrating rank in the vector autoregressive model. Econometrica 70, 1929-1961.

Johansen, S., and Juselius, K., 1990. Maximum likelihood estimation and inference on cointegration - with applications to the demand for money. Oxford Bulletin of Economics and Statistics 52, 169-210.

Johansen, S., and Juselius, K., 1992. Testing structural hypotheses in a multivariate cointegration analysis of the PPP and UIP for UK. Journal of Econometrics 53, 211-244.

Juselius, K., 1995. Do purchasing power parity and uncovered interest parity hold in the long run? An example of likelihood inference in a multivariate time-series model. Journal of Econometrics 69, 211-240.

Juselius, K., 2006. The Cointegrated VAR Model - Methodology and Applications. Oxford: Oxford University Press.

Juselius, K., and MacDonald, R., 2004. International parity relationships between the US and Japan. Japan and the World Economy 16, 17-34.

Juselius, K., and MacDonald, R., 2000. International parity relationships between Germany and the United States: A joint modelling approach. University of Copenhagen, Institute of Economics Discussion Paper 00/10.

Juselius, K., and Toro, J., 2005. Monetary transmission mechanisms in Spain: The effect of monetization, financial deregulation, and the EMS. Journal of International Money and Finance 24, 509-531.

Kilian, L. and Taylor M. P., 2003. Why is it so difficult to beat the random walk forecast of exchange rates? Journal of International Economics 60, 85-107.

Kim, Y., 1990. Purchasing power parity in the long run: A cointegration approach. Journal of Money, Credit and Banking 22, 491-503.

Koedijk, K. G., Tims, B., and van Dijk, M. A., 2004. Purchasing power parity and the Euro area. Journal of International Money and Finance. 23, 1081-1107.

Kontolemis, Z. G., and Samiei, H., 2000. The UK business cycle, monetary policy, and EMU entry. IMF Working Paper WP/00/210.

Kuo, B. S., and Mikkola, A., 1999. Re-examining long-run purchasing power parity, Journal of International Money and Finance 18, 251-266. 
Layton, A. P., and Stark, J. P., 1990. Co-integration as an empirical test of purchasing power parity. Journal of Macroeconomics 12, 125-36.

Ljung, G. M., and Box, G. E. P., 1978. On a measure of lack of fit in time series models. Biometrika 65, 297-303.

Lopez, C., and Papell, D. H., 2007. Convergence to purchasing power parity at the commencement of the Euro. Review of International Economics 15, 1-16.

Lothian, J. R., 1997. Multi-country evidence on the behavior of purchasing power parity. Journal of International Money and Finance 16, 19-35.

Lothian, J. R., and Taylor, M., 1996. Real exchange rate behavior: The recent float from the perspective of the past two centuries. Journal of Political Economy 104, 488-510.

MacDonald, R., 1996. Panel unit root tests and real exchange rates. Economics Letters 50, 7-11.

Manzur, M., and Chan, F., 2010. Exchange rate volatility and purchasing power parity: Does euro make any difference? International Journal of Banking and Finance 7, 99-118.

Mark, N. C., 1990. Real and nominal exchange rates in the long run: An empirical investigation. Journal of International Economics 28, 115-136.

Merton, R. C.,1973. An intertemporal capital asset pricing model. Econometrica 41, 867-887.

Miyakoshi, T., 2004. A testing of the purchasing power parity using a vector autoregressive model. Empirical Economics 29, 541-552.

Mussa, M., 1976. The exchange rate, the balance of payments, and monetary and fiscal policy under a regime of controlled floating. Scandinavian Journal of Economics 78, 229-248.

Nielsen, H. B., 2004. Cointegration analysis in the presence of outliers. The Econometrics Journal 7, 249-271

O’Connell, P., 1998. The overvaluation of purchasing power parity. Journal of International Economics 44, 1-19.

Osterwald-Lenum, M., 1992. A note with quantiles of the asymptotic distribution of the maximum likelihood cointegration rank test statistic. Oxford Bulletin of Economics and Statistics 54, 461-472.

Obstfeld, M., and Rogoff, K., 1995. Exchange rate dynamics redux. Journal of Political Economy 103, 624-60.

Ozmen, E., and Gokcan, A., 2004. Deviations from PPP and UIP in a financially open economy: The Turkish evidence. Applied Financial Economics 14, 779-784. 
Papell, D., 1997. Searching for stationarity: Purchasing power parity under the current float. Journal of International Economics 43, 313-332.

Papell, D. H., and Theodoridis, H., 1998. Increasing evidence of purchasing power parity over the current float. Journal of International Money and Finance 17, 41-50.

Pedersen, M., 2002a. Does the PPP hold within the US? European University Institute Working Paper ECO No. 2002/18. http://cadmus.eui.eu/bitstream/handle/1814/790/ECO2002-18.pdf?sequence=1

Pedersen, M. 2002b. Testing the PPP in a cointegrated VAR when inflation rates are nonstationary. With an application to the UK and Germany. Mimeo. Available from the author.

Pedroni, P., 1995. Panel cointegration: Asymptotic and finite sample properties of pooled time series tests with an application to the PPP hypothesis. Indiana University Working Papers in Economics 95-013.

Pedroni, P., 2001. Purchasing power parity in cointegrated panels. Review of Economics and Statistics 83, 727-731.

Pesaran, M. H., Shin, Y., and Smith, R., 2000. Structural analysis of vector error correction models with exogenous I(1) variables. Journal of Econometrics 97, 293-343.

Rapach, D. E., 2003. International evidence on the long run impact of inflation. Journal of Money, Credit, and Banking 35, 23-48.

Rogoff, K., 1996. The purchasing power parity puzzle. Journal of Economic Literature 34, 647668.

Sarno, L., and Taylor, M. P., 2002. The Economics of Exchange Rate. Cambridge University Press, Cambridge, UK.

Sjoo, B., 1995. Foreign transmission effects in Sweden: Do PPP and UIP hold in the long run? Advances in International Banking and Finance 1, 129- 149.

Snaith, S., 2012. The PPP debate: Multiple breaks and cross-sectional dependence. Economics Letters 115, 342-344.

Solnik, R. E., 1974. An equilibrium model of the international capital market. Journal of Economic Theory 8, 500-524

Stepthon, P. S., and Larsen, K. S., 1991. Tests of exchange market efficiency: fragile evidence from cointegration tests. Journal of International Money and Finance 10, 561-570. 
Taylor, M., 1988. An empirical examination of long-run purchasing power parity using cointegration techniques. Applied Economics 20, 1369-1381.

Taylor, M. P., and Sarno, L., 1998. The behaviour of real exchange rates during the post-Bretton Woods period. Journal of International Economics 46, 281-312.

Taylor, A. M., and Taylor, M. P., 2004. The purchasing power parity debate. Journal of Economic Perspectives 18, 135-158.

Wu, J., and Chen, S., 1999. Are real exchange rates stationary based on panel unit-root tests? Evidence from Pacific basin countries. International Journal of Finance and Economics 4, 243-252. 
Table 1: $\quad$ Augmented Dickey-Fuller unit root tests

\begin{tabular}{|l|c|c|c|c|}
\hline Variable & Levels & $\boldsymbol{k}$ & Differences & $\boldsymbol{k}$ \\
\hline$\Delta p_{t}$ & -2.383 & 11 & -9.083 & 10 \\
\hline$\Delta p_{t}^{*}$ & -1.552 & 12 & -6.374 & 11 \\
\hline$i_{t}$ & -1.672 & 1 & -9.279 & 0 \\
\hline$i_{t}^{*}$ & -2.140 & 1 & -6.686 & 5 \\
\hline$p p p_{t}$ & -0.778 & 1 & -10.222 & 0 \\
\hline$\Delta p_{t}-\Delta p_{t}^{*}$ & -1.658 & 12 & -8.941 & 11 \\
\hline$i_{t}-i_{t}^{*}$ & -1.687 & 0 & -12.151 & 0 \\
\hline$i_{t}-\Delta p_{t}$ & -1.327 & 11 & -9.048 & 10 \\
\hline$i_{t}^{*}-\Delta p_{t}^{*}$ & -0.751 & 12 & -6.328 & 11 \\
\hline$\left(i_{t}-\Delta p_{t}\right)-\left(i_{t}^{*}-\Delta p_{t}^{*}\right)$ & -1.884 & 12 & -8.581 & 11 \\
\hline
\end{tabular}

Note: The test critical values at the 0.01 and 0.05 levels are -3.477 and -2.881 , respectively. $k$ is the number of lags. The Akaike information criterion (AIC) selects the number of lags.

Table 2: $\quad$ Dickey-Fuller-GLS unit root tests

\begin{tabular}{|l|c|c|c|c|}
\hline Variable & Levels & $\boldsymbol{k}$ & Differences & $\boldsymbol{k}$ \\
\hline$\Delta p_{t}$ & -1.843 & 11 & -3.735 & 12 \\
\hline$\Delta p_{t}^{*}$ & -1.453 & 12 & -2.698 & 3 \\
\hline$i_{t}$ & -1.649 & 1 & -4.480 & 1 \\
\hline$i_{t}^{*}$ & -1.643 & 7 & -4.107 & 2 \\
\hline$p p p_{t}$ & -0.812 & 1 & -3.416 & 3 \\
\hline$\Delta p_{t}-\Delta p_{t}^{*}$ & -0.708 & 12 & -2.924 & 4 \\
\hline$i_{t}-i_{t}^{*}$ & -1.683 & 0 & -4.517 & 2 \\
\hline$i_{t}-\Delta p_{t}$ & -1.480 & 11 & -8.451 & 4 \\
\hline$i_{t}^{*}-\Delta p_{t}^{*}$ & -0.842 & 12 & -2.872 & 4 \\
\hline$\left(i_{t}-\Delta p_{t}\right)-\left(i_{t}^{*}-\Delta p_{t}^{*}\right)$ & -0.932 & 12 & -4.706 & 2 \\
\hline
\end{tabular}

Note: The test critical values at the 0.01 and 0.05 levels are -2.582 and -1.943 , respectively. $k$ is the number of lags. The Akaike information criterion (AIC) selects the number of lags. 
Table 3: $\quad$ Specification tests (full rank model)

\begin{tabular}{|c|c|c|c|c|c|}
\hline \multicolumn{6}{|c|}{ A. Multivariate tests } \\
\hline \multicolumn{6}{|c|}{ Tests for autocorrelation } \\
\hline LM(1): & \multicolumn{2}{|c|}{$\chi^{2}(25)$} & \multicolumn{2}{|c|}{38.357} & [0.043] \\
\hline LM(2): & \multicolumn{2}{|c|}{$\chi^{2}(25)$} & \multicolumn{2}{|c|}{36.967} & [0.058] \\
\hline \multicolumn{6}{|c|}{ Test for Normality } \\
\hline & \multicolumn{2}{|c|}{$\chi^{2}(10)$} & \multicolumn{2}{|c|}{12.020} & [0.284] \\
\hline \multicolumn{6}{|c|}{ Test for ARCH } \\
\hline LM(1): & \multicolumn{2}{|c|}{$\chi^{2}(225)$} & \multicolumn{2}{|c|}{282.807} & [0.005] \\
\hline LM(2): & \multicolumn{2}{|c|}{$\chi^{2}(450)$} & \multicolumn{2}{|c|}{512.408} & [0.022] \\
\hline \multicolumn{6}{|c|}{ B. Univariate tests } \\
\hline & \multicolumn{2}{|c|}{$\operatorname{ARCH}(3)$} & \multicolumn{2}{|c|}{ Normality } & $R^{2}$ \\
\hline$\Delta^{2} p_{t}$ & 4.192 & [0.241] & 1.337 & {$[0.512]$} & 0.900 \\
\hline$\Delta^{2} p_{t}^{*}$ & 0.307 & [0.959] & 1.380 & {$[0.501]$} & 0.883 \\
\hline$\Delta p p p_{t}$ & 0.648 & [0.885] & 5.394 & {$[0.067]$} & 0.471 \\
\hline$\Delta i_{t}$ & 1.535 & [0.674] & 0.145 & {$[0.930]$} & 0.313 \\
\hline$\Delta i_{t}^{*}$ & 6.118 & {$[0.106]$} & 0.087 & {$[0.957]$} & 0.336 \\
\hline
\end{tabular}

Note: The multivariate LM test statistic is asymptotically distributed as $\chi^{2}$ with $p^{2}$ degrees of freedom (Johansen, 1995). The multivariate and univariate normality tests are asymptotically $\chi^{2}$ distributed, with $2 p$ degrees of freedom in the multivariate and 2degrees of freedom in the univariate case, respectively (Doornik and Hansen, 2008). The multivariate ARCH test statistic is approximately distributed as $\chi^{2}$ with $\frac{q}{4} p^{2}(p+1)^{2}$ degrees of freedom. The univariate ARCH test is approximately distributed as $\chi^{2}$ with $k$ degrees of freedom (Dennis et al., 2006).

Table 4: $\quad$ Tests for cointegration rank

\begin{tabular}{|c|c|c|c|c|c|c|c|}
\hline$(p-r)$ & $r$ & $\lambda_{i}$ & $Q_{r}$ & $Q_{r}^{*}$ & $C_{0.95 \%}^{D}$ & $p$-value & $p$-value* \\
\hline 5 & 0 & 0.364 & 159.978 & 148.877 & 87.333 & 0.000 & 0.000 \\
\hline 4 & 1 & 0.313 & 94.898 & 89.150 & 63.677 & 0.000 & 0.001 \\
\hline 3 & 2 & 0.158 & 40.789 & 38.568 & 42.883 & 0.078 & 0.124 \\
\hline 2 & 3 & 0.078 & 16.076 & 15.232 & 25.772 & 0.476 & 0.543 \\
\hline 1 & 4 & 0.030 & 4.321 & 4.126 & 12.023 & 0.669 & 0.696 \\
\hline
\end{tabular}

Note: In addition to the number of common trends $(p-r)$ and cointegrating vectors $(r)$, this table reports the estimated eigenvalues $\lambda_{i}$, the trace statistics $Q_{r}$, the Bartlett small-sample corrected trace statistics, $Q_{r}^{*}$, the 95-percent quantile from the asymptotic distribution corrected for deterministic component, $C_{0.95 \%}^{D}$, obtained using 2500 simulations, as well as the $p$-value of the test statistic and the $p$-value* of the Bartlett small-sample correction. 
Table 5: Modulus of the ten largest roots of the companion matrix of the VAR model

\begin{tabular}{|c|c|c|c|c|c|}
\hline$r=0$ & $r=1$ & $r=2$ & $r=3$ & $r=4$ & $r=5$ \\
\hline 1 & 1 & 1 & 1 & 1 & 0.938 \\
\hline 1 & 1 & 1 & 1 & 0.874 & 0.904 \\
\hline 1 & 1 & 1 & 0.782 & 0.659 & 0.654 \\
\hline 1 & 1 & 0.562 & 0.569 & 0.659 & 0.654 \\
\hline 1 & 0.572 & 0.562 & 0.569 & 0.566 & 0.568 \\
\hline 0.640 & 0.572 & 0.558 & 0.543 & 0.566 & 0.568 \\
\hline 0.640 & 0.541 & 0.558 & 0.543 & 0.545 & 0.545 \\
\hline 0.571 & 0.541 & 0.514 & 0.535 & 0.454 & 0.545 \\
\hline 0.571 & 0.530 & 0.514 & 0.535 & 0.454 & 0.535 \\
\hline 0.481 & 0.530 & 0.497 & 0.496 & 0.409 & 0.535 \\
\hline
\end{tabular}

Note: The table shows the modulus of the estimated $p x k$ roots of the companion matrix from the VAR system, $p$ is the number of variables and $k$ is the number of lags of the VAR. The eigenvalues, $\lambda_{i}$ and the roots, $\hat{\rho}_{i}$, relate to each other as follows: $\lambda_{i}=1-\hat{\rho}_{i}$. For example, $\lambda_{i}=0$ implies $\hat{\rho}_{i}=1$, which corresponds to a unit-root process.

Table 6: $\quad$ Tests of Long-Run Exclusion and Weak Exogeneity

Panel A: Tests of Long-Run Exclusion

\begin{tabular}{|c|c|c|c|c|c|c|c|c|c|}
\hline$r$ & $d f$ & $5 \%$ C.V. & $\Delta p_{t}$ & $\Delta p_{t}^{*}$ & $i_{t}$ & $i_{t}^{*}$ & $p p p_{t}$ & $C_{200710}$ & constant \\
\hline 2 & 2 & 5.991 & 40.036 & 32.959 & 11.738 & 6.985 & 8.726 & 10.737 & 7.538 \\
\hline & & & {$[0.000]$} & {$[0.000]$} & {$[0.003]$} & {$[0.030]$} & {$[0.013]$} & {$[0.005]$} & {$[0.023]$} \\
\hline
\end{tabular}

Panel B: Tests of Long-Run Weak Exogeneity

\begin{tabular}{|c|c|c|c|c|c|c|c|}
\hline$r$ & $d f$ & $5 \%$ C.V. & $\Delta p_{t}$ & $\Delta p_{t}^{*}$ & $i_{t}$ & $i_{t}^{*}$ & $p p p_{t}$ \\
\hline 2 & 2 & 5.991 & 33.627 & 28.594 & 5.571 & 3.961 & 3.115 \\
\hline & & & {$[0.000]$} & {$[0.000]$} & {$[0.062]$} & {$[0.138]$} & {$[0.211]$} \\
\hline
\end{tabular}

Notes: Numbers in brackets report $p$-values. The tests of long-run weak exogeneity restriction tests for the null hypothesis $\alpha_{i}=0$. The tests are LR tests distributed as $\chi^{2}(r)$ 
Table 7: $\quad$ Tests of cointegrating relations

\begin{tabular}{|l|c|c|c|c|c|c|c|c|c|}
\hline & $\Delta p_{t}$ & $\Delta p_{t}^{*}$ & $i_{t}$ & $i_{t}^{*}$ & $p p p_{t}$ & $C_{200710}$ & constant & $\chi^{2}(v)$ & $p$-value \\
\hline$H_{1}$ & 0 & 0 & 0 & 0 & 1 & -0.002 & 0.004 & $36.091(3)$ & 0.000 \\
\hline$H_{2}$ & 1 & -1 & 0 & 0 & 0 & 0.002 & 0.000 & $5.512(3)$ & 0.138 \\
\hline$H_{3}$ & 0 & 0 & 1 & -1 & 0 & 0.000 & 0.000 & $49.697(3)$ & 0.000 \\
\hline$H_{4}$ & 1 & 0 & -1 & 0 & 0 & -0.001 & 0.002 & $22.230(3)$ & 0.000 \\
\hline$H_{5}$ & 0 & 1 & 0 & -1 & 0 & -0.003 & 0.003 & $12.820(3)$ & 0.005 \\
\hline$H_{6}$ & 1 & -1 & -1 & 1 & 0 & 0.002 & -0.001 & $9.050(3)$ & 0.029 \\
\hline$H_{7}$ & 1 & -1 & 0.06 & -0.06 & 0 & 0.002 & 0.000 & $5.500(2)$ & 0.064 \\
\hline$H_{8}$ & 1 & -1.55 & -1 & 1.55 & 0 & 0.003 & -0.002 & $6.86(2)$ & 0.032 \\
\hline$H_{9}$ & 1 & -1 & 0 & 0 & 0.502 & 0.001 & 0.002 & $3.912(2)$ & 0.203 \\
\hline$H_{9 A}$ & -0.64 & 1.00 & 0 & 0 & -0.352 & -0.001 & -0.002 & $2.051(1)$ & 0.152 \\
\hline$H_{10}$ & 0 & 0 & 1 & -1 & 1.011 & -0.002 & 0.005 & $30.803(2)$ & 0.000 \\
\hline$H_{11}$ & 1 & 0 & -1 & 0 & -0.767 & 0.001 & 0.001 & $19.947(2)$ & 0.000 \\
\hline$H_{12}$ & 0 & 1 & 0 & -1 & -0.7 & -0.002 & 0.002 & $10.327(2)$ & 0.006 \\
\hline$H_{13}$ & 1 & -1 & -1 & 1 & 0.086 & 0.002 & 0.000 & $8.979(2)$ & 0.011 \\
\hline$H_{14}$ & -0.64 & 1.00 & 0 & 0 & -0.352 & -0.001 & -0.002 & $2.051(1)$ & 0.152 \\
\hline$H_{15}$ & -1 & 2.175 & 1 & 0 & 0 & -0.003 & -0.005 & $0.775(2)$ & 0.686 \\
\hline
\end{tabular}

Notes: $\quad v$ is the number of degrees of freedom, defined as $v=k-(r-1)$, where $k$ is the number of restrictions.

Table 8: A structural representation of the cointegration space

\begin{tabular}{|l|c|c|c|c|c|c|c|}
\hline & $\Delta p_{t}$ & $\Delta p_{t}^{*}$ & $i_{t}$ & $i_{t}^{*}$ & $p p p_{t}$ & $C_{200710}$ & constant \\
\hline$\hat{\beta}_{1}^{\prime}$ & 1.000 & -1.000 & 0.000 & 0.000 & 0.515 & 0.001 & 0.002 \\
& (NA) & (NA) & (NA) & (NA) & $(3.715)$ & $(1.899)$ & $(3.340)$ \\
\hline$\hat{\beta}_{2}^{\prime}$ & -0.468 & 1.000 & 0.468 & 0.000 & 0.000 & -0.002 & 0.002 \\
& $(-8.838)$ & (NA) & $(8.838)$ & (NA) & (NA) & $(-5.436)$ & $(-11.572)$ \\
\hline
\end{tabular}

Notes: Numbers in parenthesis report $t$-statistics, where applicable. 
Table 9: $\quad$ Parameter estimates of the $\alpha$ matrix

\begin{tabular}{|l|c|c|}
\hline & $\hat{\alpha}_{1}$ & $\hat{\alpha}_{2}$ \\
\hline$\Delta^{2} p_{t}$ & -2.423 & -2.207 \\
\hline & $(-8.038)$ & $(-6.530)$ \\
\hline$\Delta^{2} p_{t}^{*}$ & -0.732 & -1.743 \\
\hline & $(-2.608)$ & $(-5.540)$ \\
\hline$\Delta i_{t}$ & 0.000 & 0.000 \\
\hline & $(0.000)$ & $(0.000)$ \\
\hline$\Delta i_{t}^{*}$ & 0.000 & 0.000 \\
\hline & $(0.000)$ & $(0.000)$ \\
\hline$\Delta p p p_{t}$ & 0.000 & 0.000 \\
\hline & $(0.000)$ & $(0.000)$ \\
\hline
\end{tabular}

Notes: Numbers in parenthesis report $t$-statistics.

Table 10: $\quad$ Parameter estimates of the $\Pi$ matrix

\begin{tabular}{|l|c|c|c|c|c|c|c|}
\hline & $\Delta p_{t}$ & $\Delta p_{t}^{*}$ & $i_{t}$ & $i_{t}^{*}$ & $p p p_{t}$ & $C_{2007: 10}$ & constant \\
\hline$\Delta^{2} p_{t}$ & -1.391 & 0.216 & -1.032 & 0.000 & -1.248 & 0.002 & 0.000 \\
\hline & $(-7.616)$ & $(1.276)$ & $(-6.530)$ & $(\mathrm{NA})$ & $(-8.038)$ & $(4.460)$ & $(0.143)$ \\
\hline$\Delta^{2} p_{t}^{*}$ & 0.083 & -1.011 & -0.815 & 0.000 & -0.377 & 0.002 & 0.002 \\
\hline & $(0.489$ & $(-6.412)$ & $(-5.540)$ & $(\mathrm{NA})$ & $(-2.608)$ & $(6.716)$ & $(6.830)$ \\
\hline$\Delta i_{t}$ & 0.000 & 0.000 & 0.000 & 0.000 & 0.000 & 0.000 & 0.000 \\
\hline & $(0.000)$ & $(0.000)$ & $(0.000)$ & $(\mathrm{NA})$ & $(0.000)$ & $(0.000)$ & $(0.000)$ \\
\hline$\Delta i_{t}^{*}$ & 0.000 & 0.000 & 0.000 & 0.000 & 0.000 & 0.000 & 0.000 \\
\hline & $(0.000)$ & $(0.000)$ & $(0.000)$ & $(\mathrm{NA})$ & $(0.000)$ & $(0000)$ & $(0.000)$ \\
\hline$\Delta p p p_{t}$ & 0.000 & 0.000 & 0.000 & 0.000 & 0.000 & 0.000 & 0.000 \\
\hline & $(0.000)$ & $(0.000)$ & $(0.000)$ & (NA) & $(0.000)$ & $(0.000)$ & $(0.000)$ \\
\hline
\end{tabular}

Notes: Numbers in parenthesis report $t$-statistics. 
Table 11: Estimates of the coefficients of the common trends: $\alpha_{\perp}$

\begin{tabular}{|l|c|c|c|}
\hline & Common Trend 1 & Common Trend 2 & Common Trend 3 \\
\hline$\Delta p_{t}$ & 0.000 & 0.000 & 0.000 \\
\hline & (NA) & (NA) & (NA) \\
\hline$\Delta p_{t}^{*}$ & 0.000 & 0.000 & 0.000 \\
\hline & (NA) & (NA) & (NA) \\
\hline$i_{t}$ & 1.000 & 0.000 & 0.000 \\
\hline & (NA) & (NA) & (NA) \\
\hline$i_{t}^{*}$ & 0.000 & 1.000 & 0.000 \\
\hline & (NA) & (NA) & (NA) \\
\hline$p p p_{t}$ & 0.000 & 0.000 & 1.000 \\
\hline & (NA) & (NA) & (NA) \\
\hline
\end{tabular}

Notes: Numbers in parenthesis report $t$-statistics.

Table 12: $\quad$ Estimates of the loadings to the common trends: $\beta_{\perp}$

\begin{tabular}{|l|c|c|c|}
\hline & Common Trend 1 & Common Trend 2 & Common Trend 3 \\
\hline$\Delta p_{t}$ & -1.094 & -0.033 & -1.107 \\
\hline & $(-2.683)$ & $(-0.094)$ & $(-6.392)$ \\
\hline$\Delta p_{t}^{*}$ & -1.242 & 0.108 & -0.505 \\
\hline & $(-3.998)$ & $(0.403)$ & $(-3.826)$ \\
\hline$i_{t}$ & 1.562 & -0.265 & -0.028 \\
\hline & $(4.502)$ & $(-0.881)$ & $(-0.188)$ \\
\hline$i_{t}^{*}$ & 0.436 & 0.813 & 0.078 \\
\hline & $(1.387)$ & $(2.979)$ & $(0.580)$ \\
\hline$p p p_{t}$ & -0.287 & 0.275 & 1.170 \\
\hline & $(-0.789)$ & $(0.873)$ & $(7.585)$ \\
\hline
\end{tabular}

Notes: Numbers in parenthesis report $t$-statistics. 
Table 13: $\quad$ Estimates of the long-run impact matrix: $C$

\begin{tabular}{|l|c|c|c|c|c|}
\hline & $\sum \varepsilon_{\Delta p_{t}}$ & $\sum \varepsilon_{\Delta p_{t}^{*}}$ & $\sum \varepsilon_{i_{t}}$ & $\sum \varepsilon_{i_{t}^{*}}$ & $\sum \varepsilon_{p p p_{t}}$ \\
\hline$\Delta p_{t}$ & 0.000 & 0.000 & -1.094 & -0.033 & -1.107 \\
\hline & $(0.000)$ & $(0.000)$ & $(-2.683)$ & $(-0.094)$ & $(-6.392)$ \\
\hline$\Delta p_{t}^{*}$ & 0.000 & 0.000 & -1.242 & 0.108 & -0.505 \\
\hline & $(0.000)$ & $(0.000)$ & $(-3.998)$ & $(0.403)$ & $(-3.826)$ \\
\hline$i_{t}$ & 0.000 & 0.000 & 1.562 & -0.265 & -0.028 \\
\hline & $(0.000)$ & $(0.000)$ & $(4.502)$ & $(-0.881)$ & $(-0.188)$ \\
\hline$i_{t}^{*}$ & 0.000 & 0.000 & 0.436 & 0.813 & 0.078 \\
\hline & $(0.000)$ & $(0.000)$ & $(1.387)$ & $(2.979)$ & $(0.580)$ \\
\hline$p p p_{t}$ & 0.000 & 0.000 & -0.287 & 0.275 & 1.170 \\
\hline & $(0.000)$ & $(0.000)$ & $(-0.789)$ & $(0.873)$ & $(7.585)$ \\
\hline
\end{tabular}

Notes: Numbers in parenthesis report $t$-statistics. 

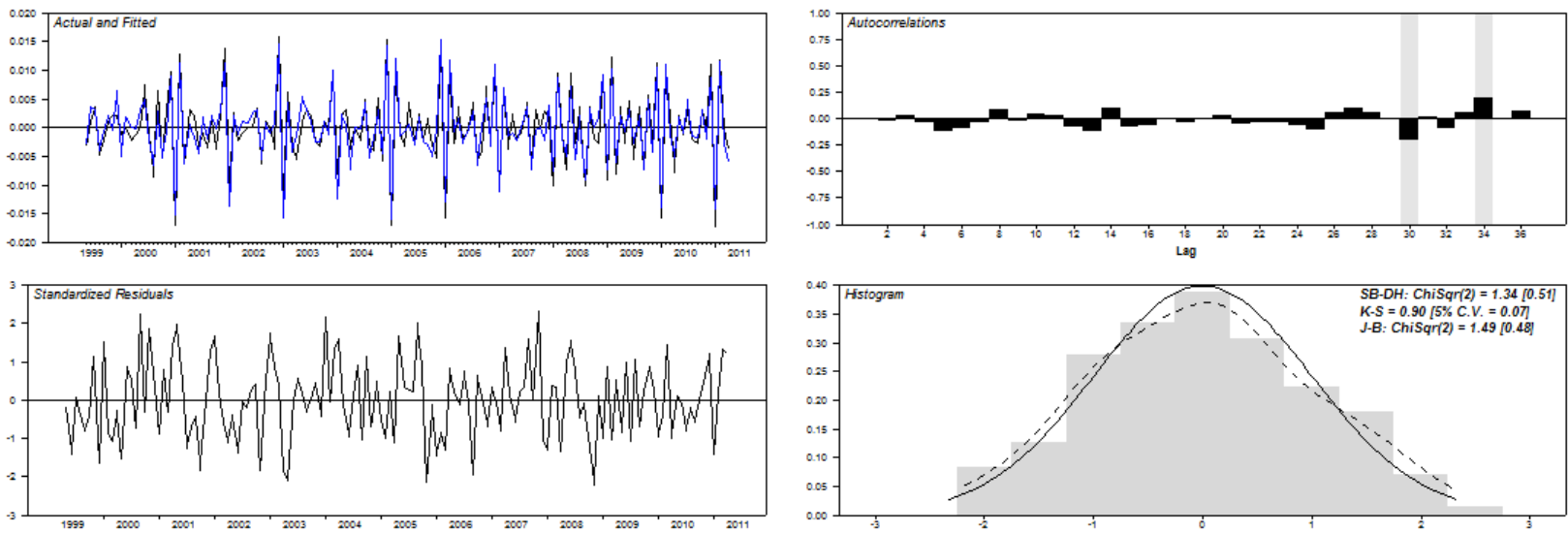

Figure 1: $\quad$ Graphical analysis of the $\Delta p_{t}$ residuals
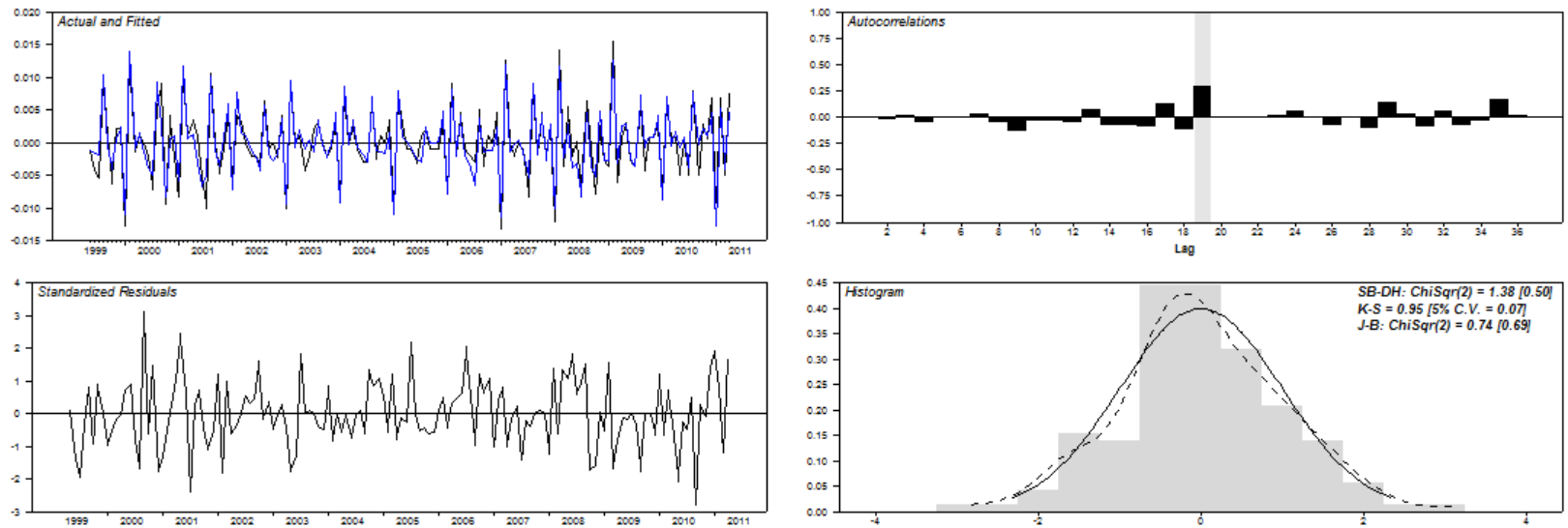

Figure 2: $\quad$ Graphical analysis of the $\Delta p_{t}^{*}$ residuals
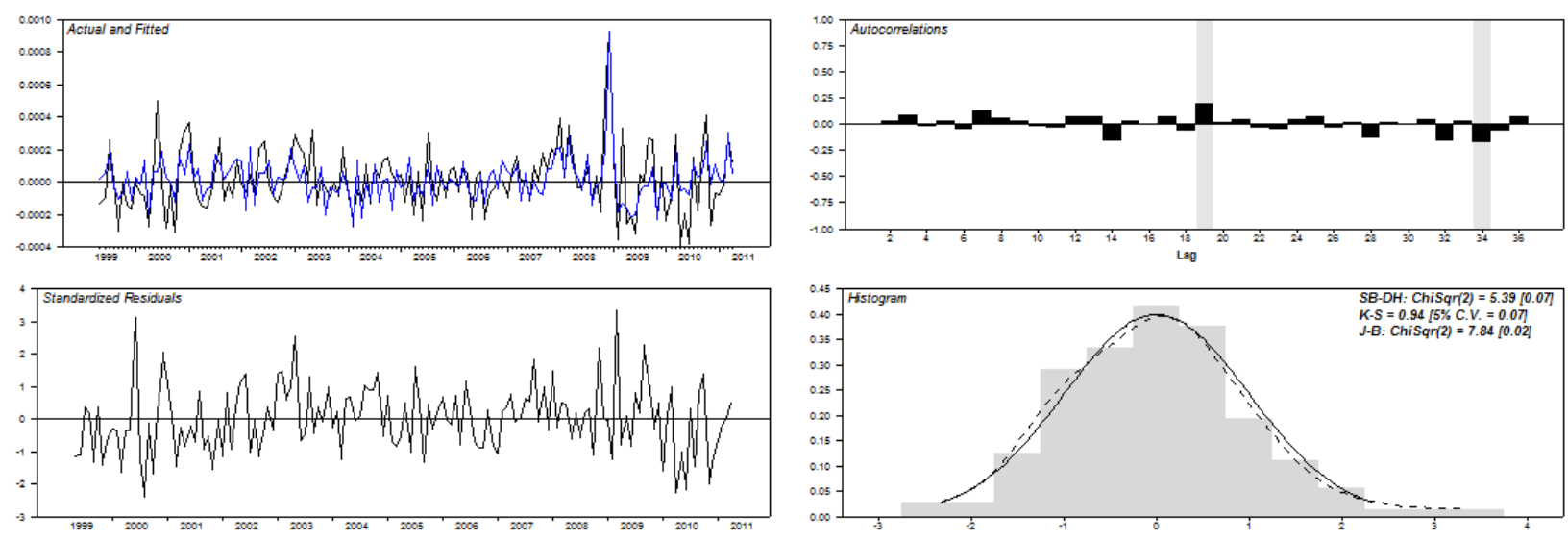

Figure 3: Graphical analysis of the $p p p_{t}$ residuals 

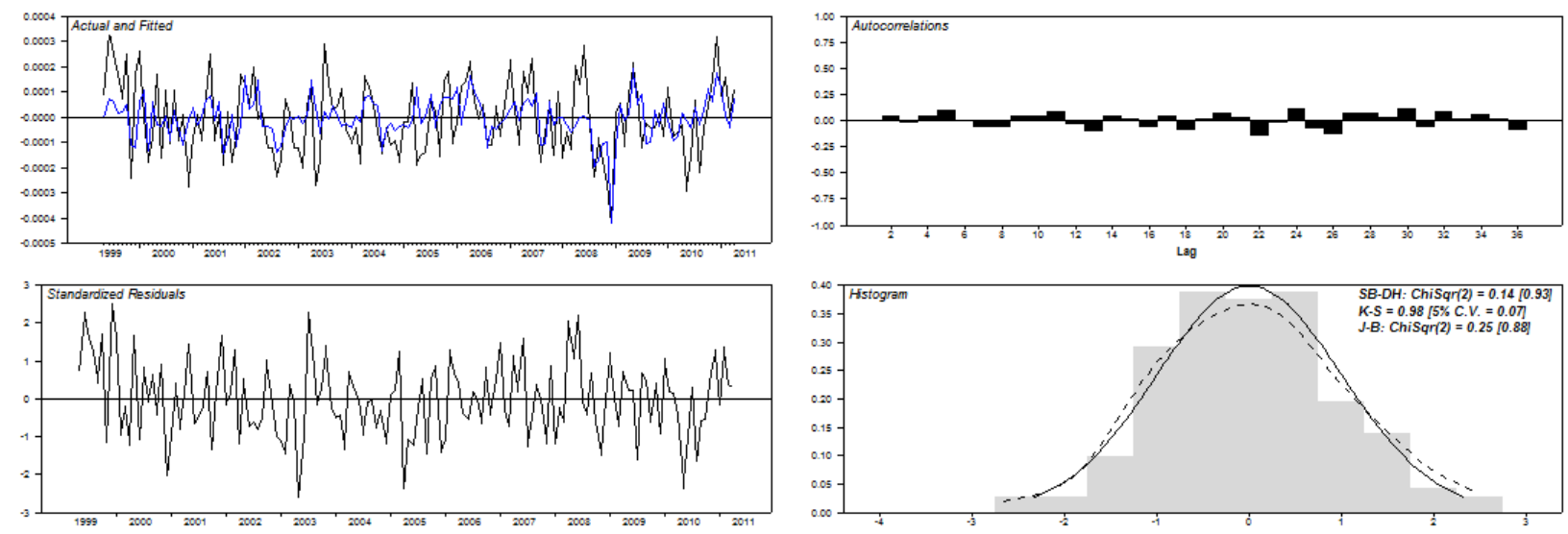

Figure 4: Graphical analysis of the $i_{t}$ residuals
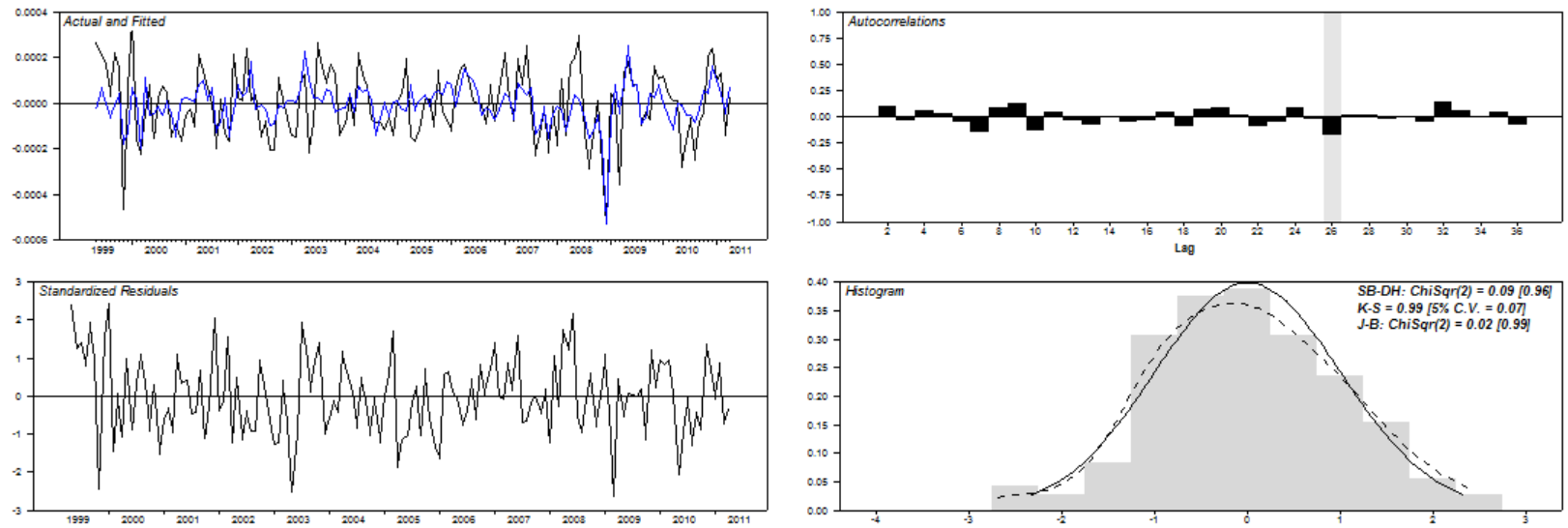

Figure 5: Graphical analysis of the $i_{t}^{*}$ residuals 

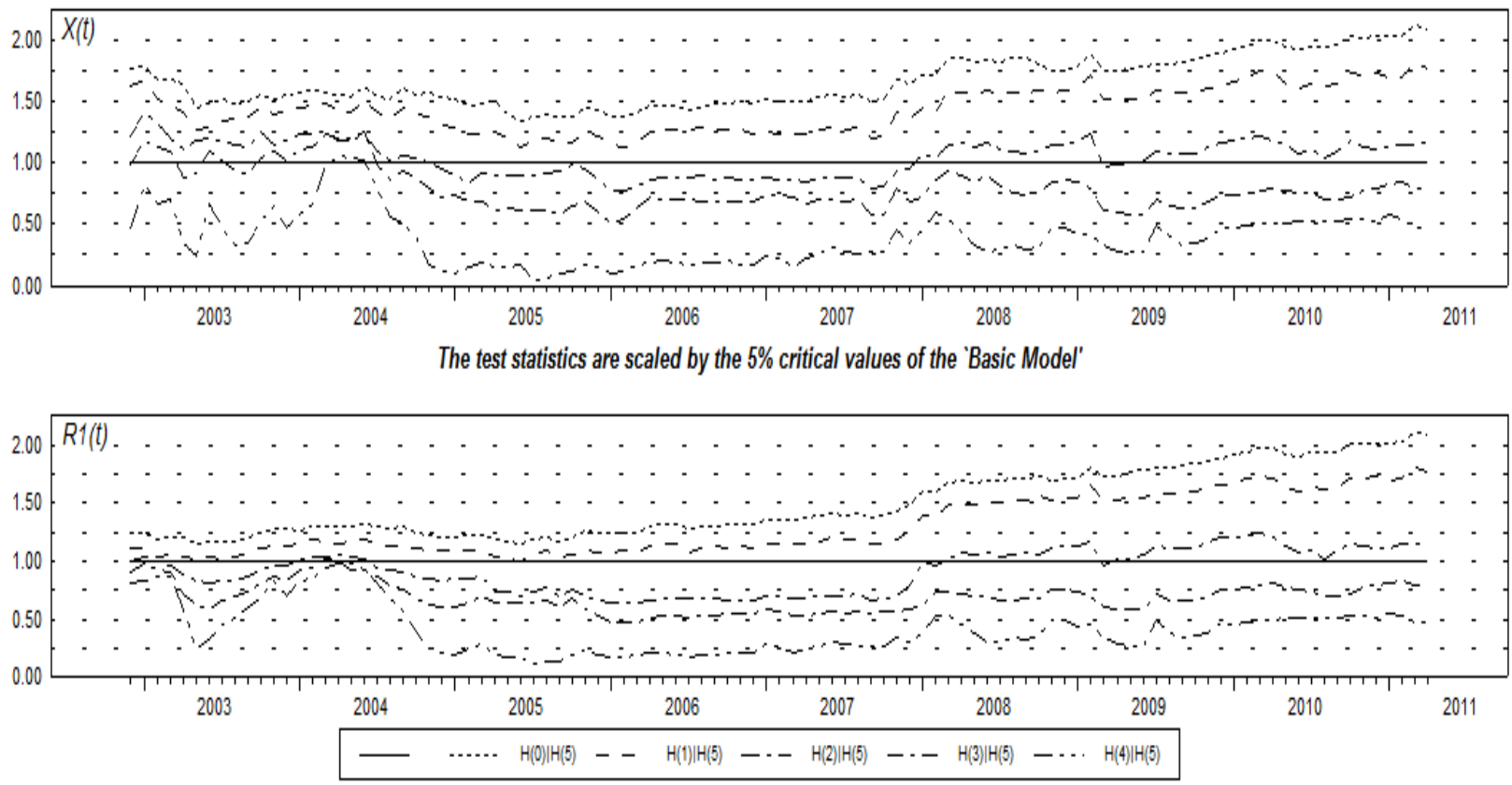

Figure 6: The recursively calculated trace test statistics
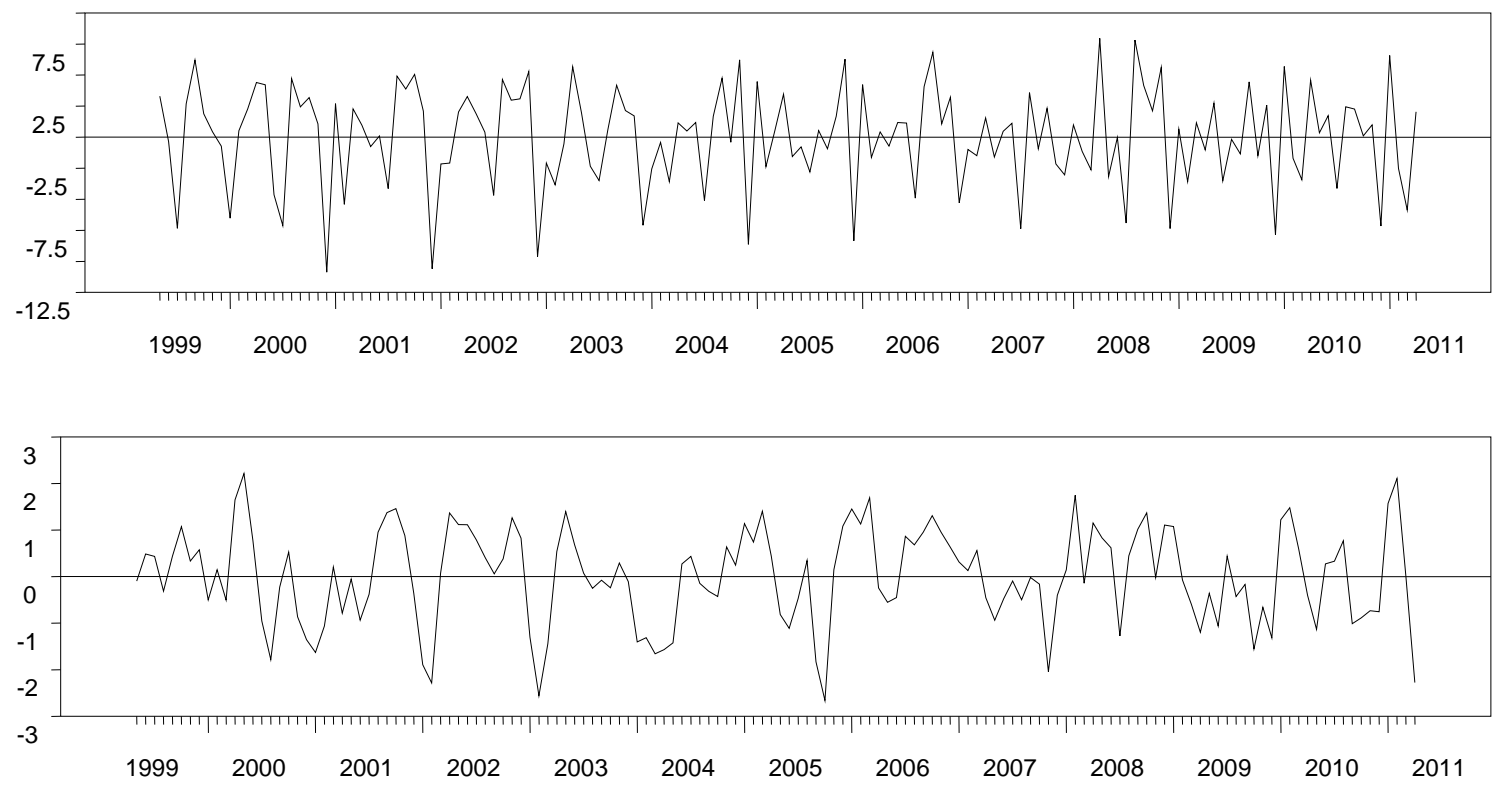

Figure 7: The first cointegrating relationship, $\widehat{\beta}_{1}^{\prime} X_{1 t}$ and $\widehat{\beta}_{1}^{\prime} R_{1 t}$ 

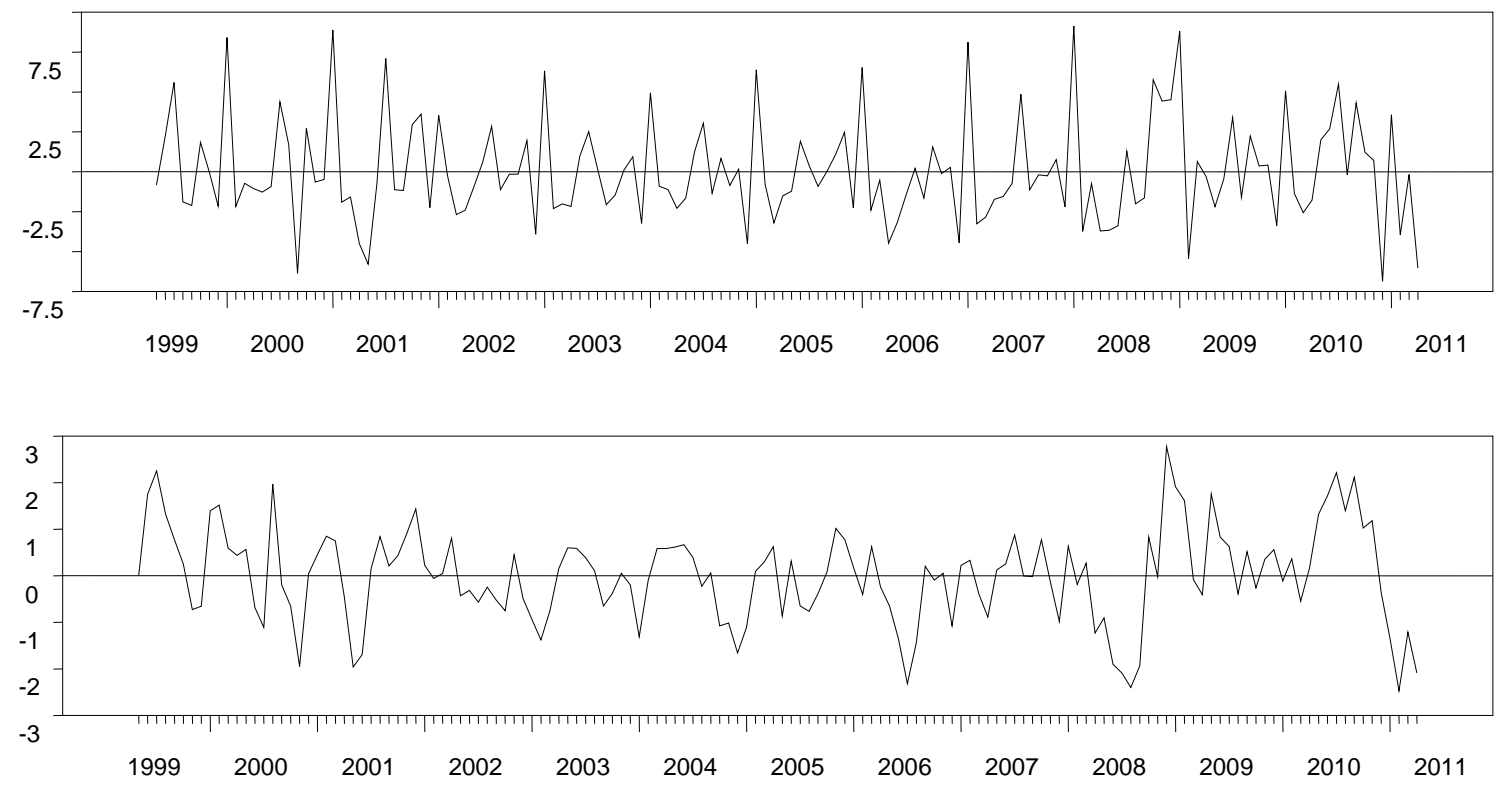

Figure 8: The second cointegrating relationship, $\widehat{\boldsymbol{\beta}}_{2}^{\prime} X_{2 t}$ and $\widehat{\boldsymbol{\beta}}_{2}^{\prime} R_{2 t}$
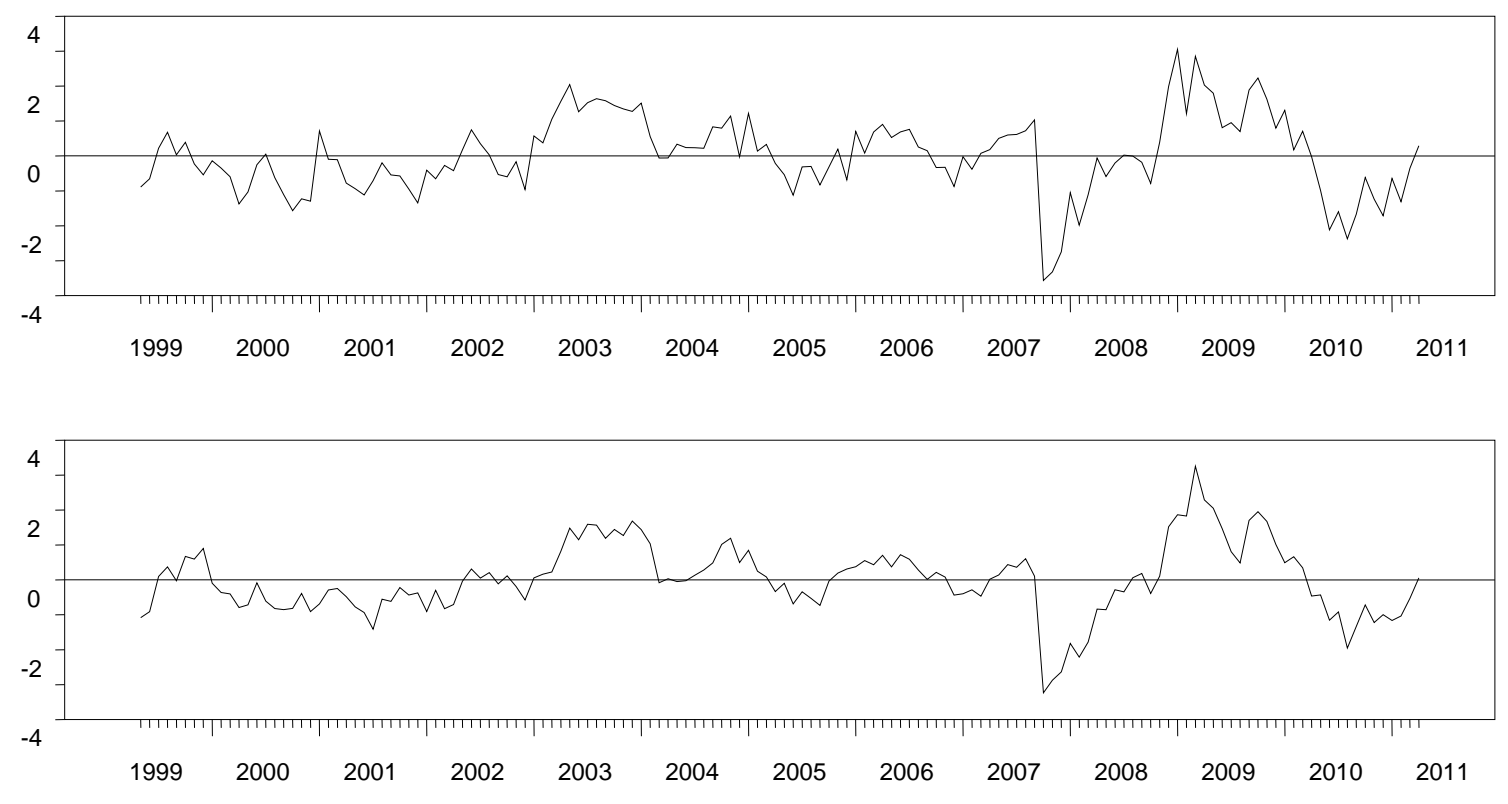

Figure 9: The third cointegrating relationship, $\widehat{\boldsymbol{\beta}}_{3}^{\prime} X_{3 t}$ and $\widehat{\boldsymbol{\beta}}_{3}^{\prime} R_{3 t}$ 

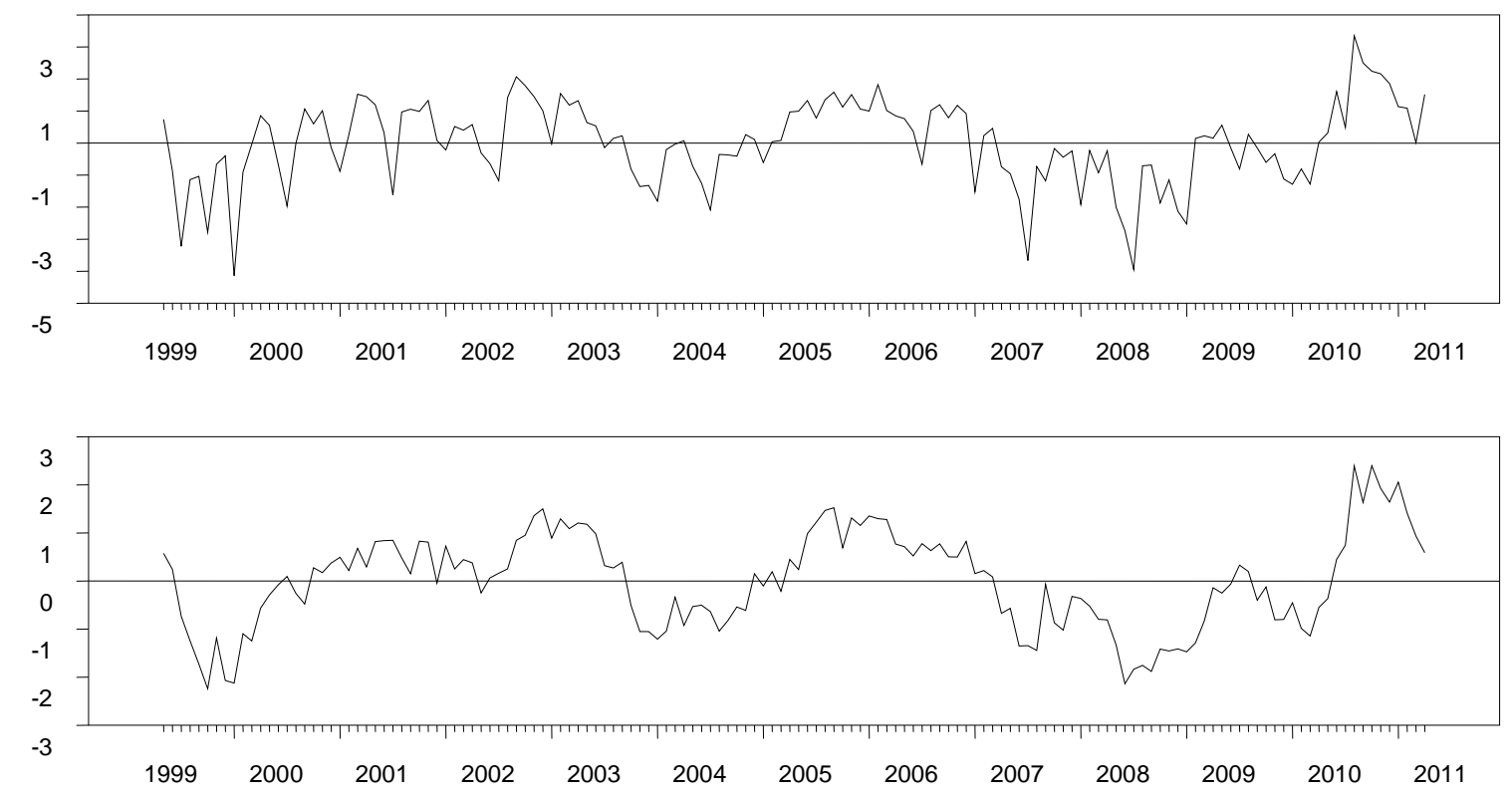

Figure 10: The fourth cointegrating relationship, $\widehat{\beta}_{4}^{\prime} X_{4 t}$ and $\widehat{\beta}_{4}^{\prime} R_{4 t}$
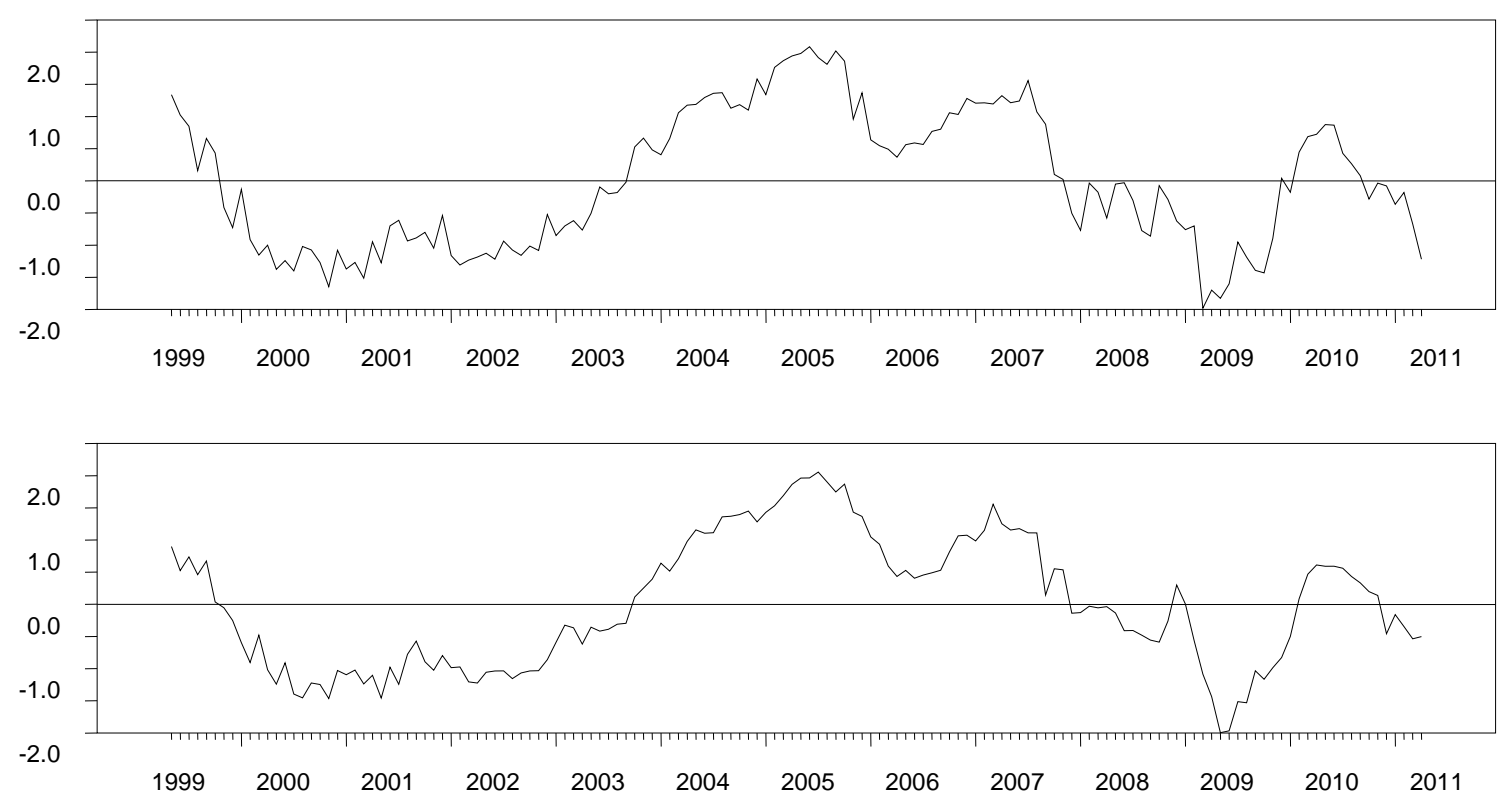

Figure 11: The fifth cointegrating relationship, $\widehat{\boldsymbol{\beta}}_{5}^{\prime} X_{5 t}$ and $\widehat{\beta}_{5}^{\prime} R_{5 t}$ 

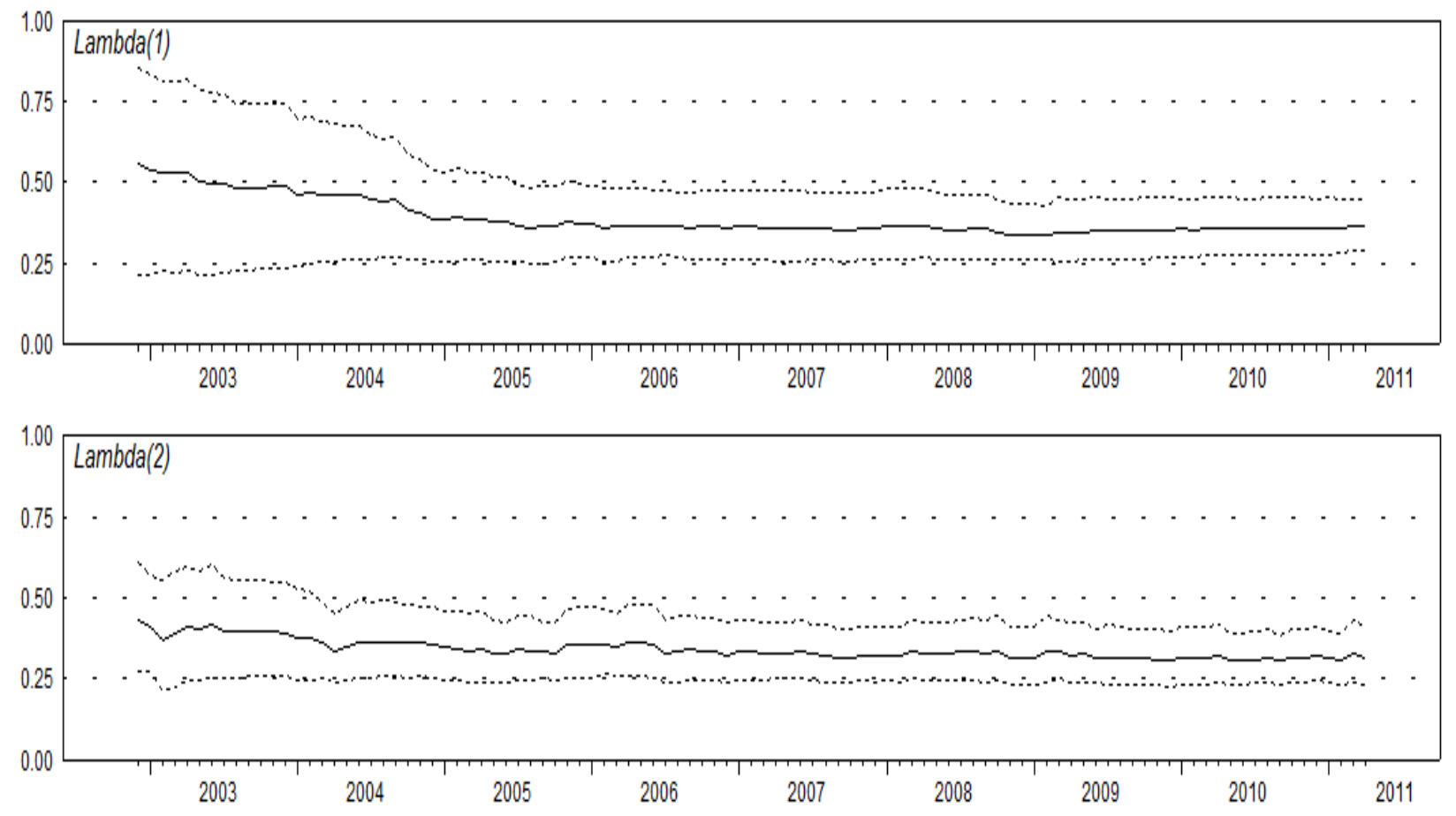

Figure 12: The time paths of the eigenvalues $\lambda_{1}$ and $\lambda_{2}$ with $95 \%$ confidence bands (dotted lines).
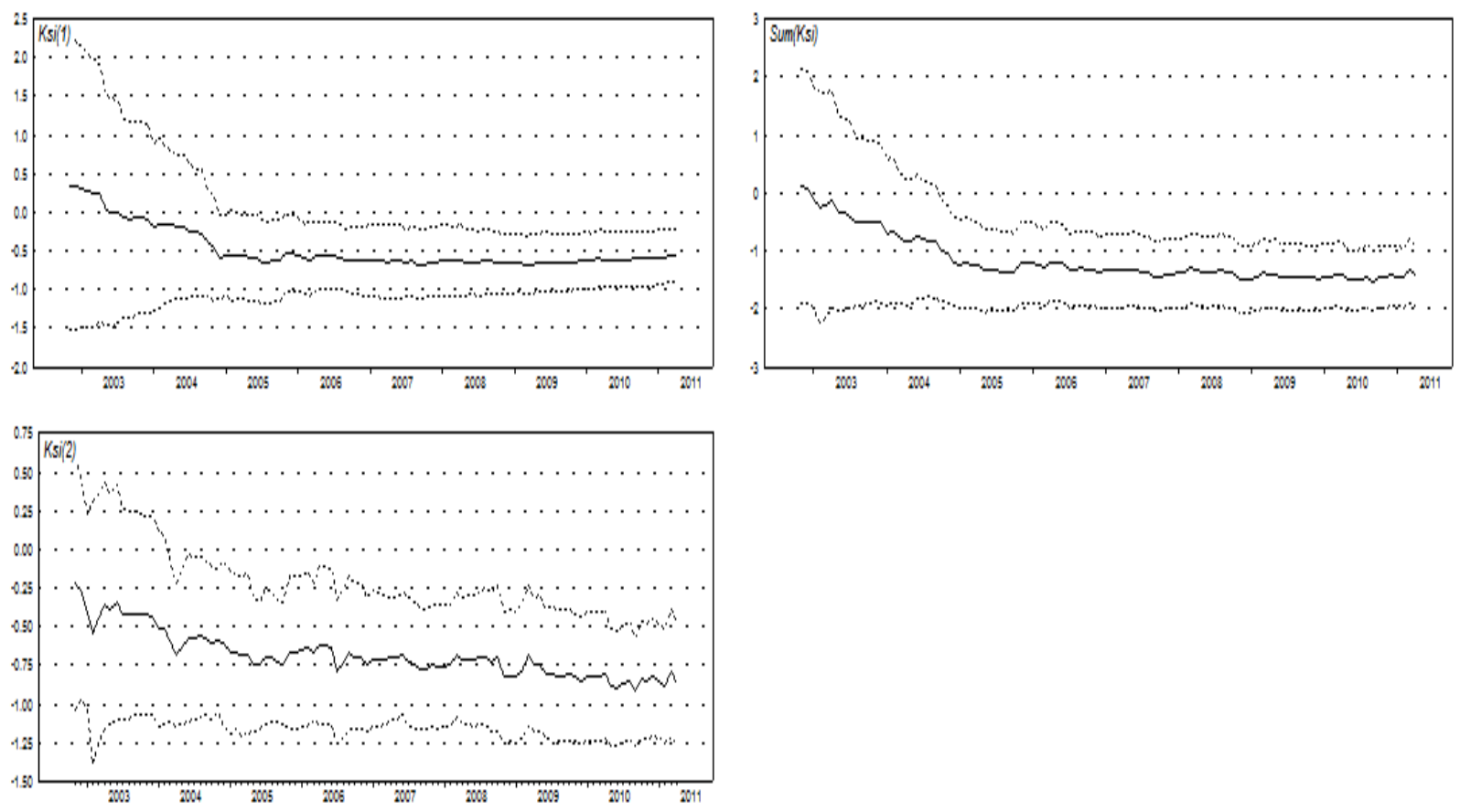

Figure 13: The time paths of the transformed eigenvalues $\xi_{1}$ and $\xi_{2}$ and their sum with $95 \%$ confidence bands (dotted lines). 

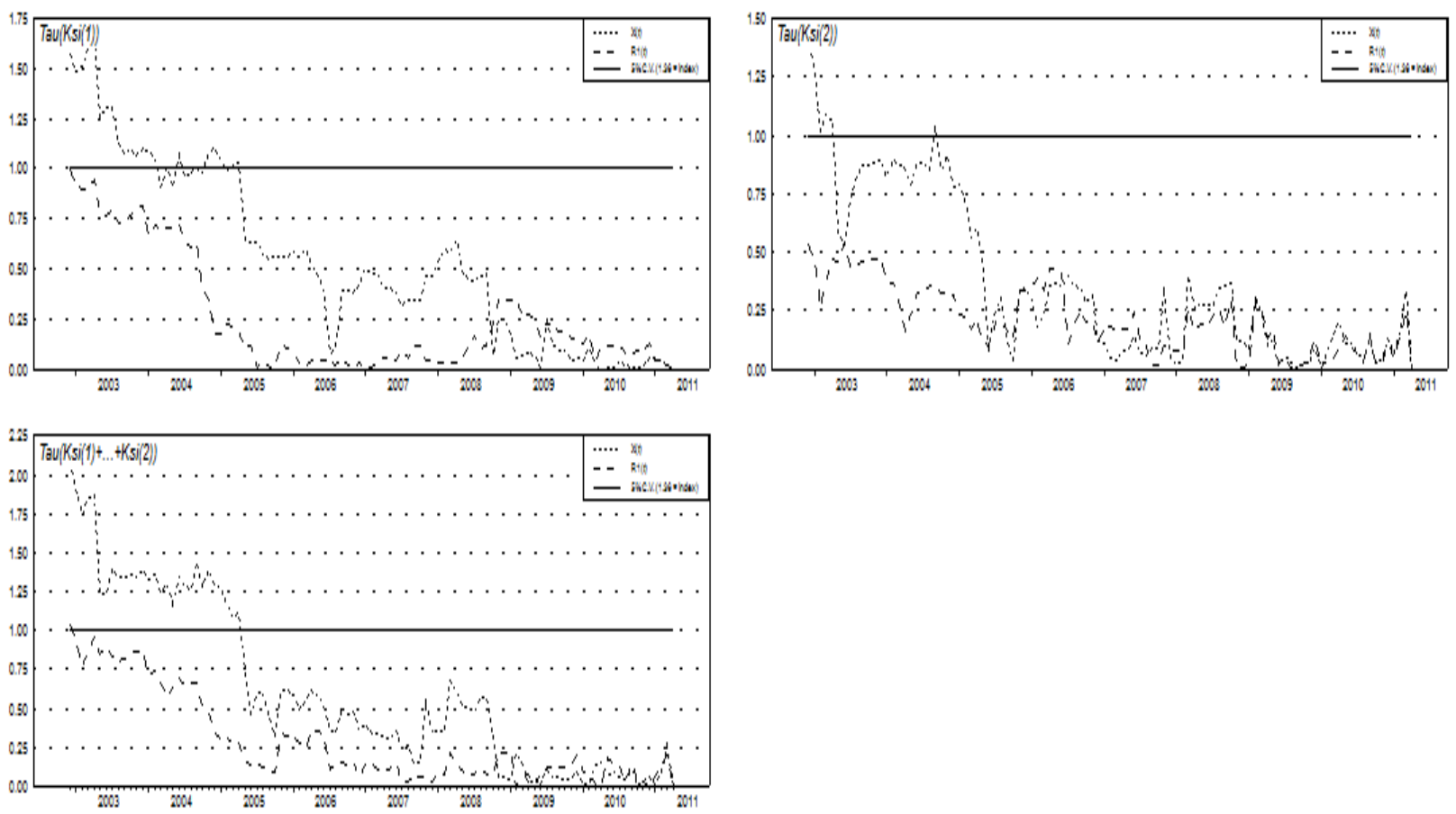

Figure 14: Fluctuation tests of the transformed eigenvalues and their sum for the $X(t)$ form (dotted line) and the R1(t)-form (dashed line). The graphs are scaled by the $5 \%$ critical value (1.36) marked by the horizontal line.

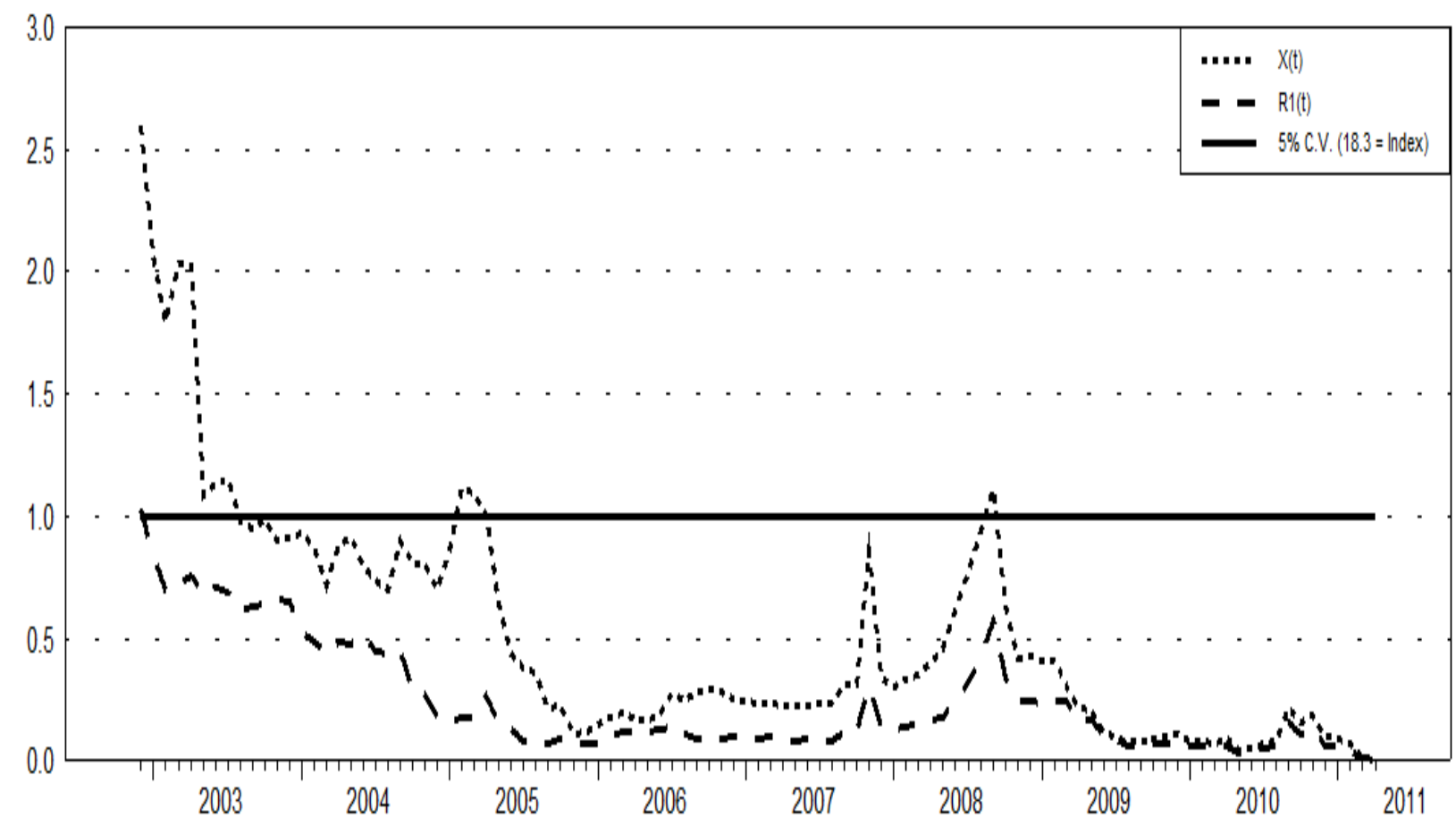

Figure 15: Time path for the tests for $\beta_{t}$ equal to known $\beta$ scaled by the $5 \%$ critical value. The $X(t)$-form is represented by the dotted line and the $R 1(t)$-form by the dashed line. 


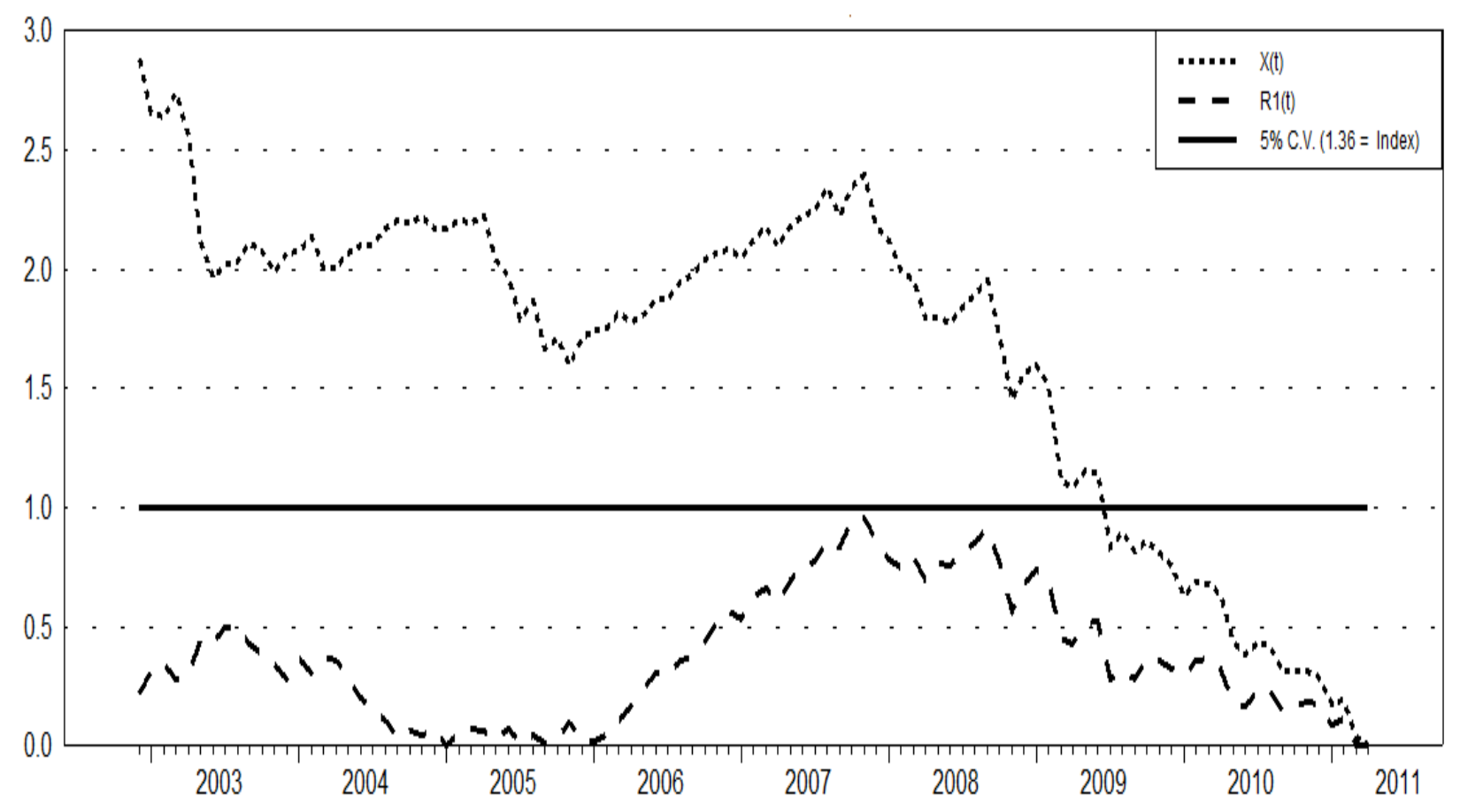

Figure 16: Time path of the log-likelihood function plotted for the $X(t)$-form (dotted line) and the R1(t)-form (dashed line). 